Volume (3) No. (1) 2020

المنهج المتمايز في الألفية الثالثة بين رأس المال الفكري واقتصاد المعرفة

أ.د/ طاهر محمد الهادي - اهي 


\section{المنهج المتحايز في الألفية الثالثة بين رأس المال الفكري واقتصاد المعرفة}

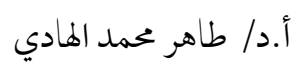

أستاذ المناهج وطرق تدريس اللغة الإنجليزية، كلية التربية، جامعة قناة السويس، مصر

\section{talhadi57@gmail.com}

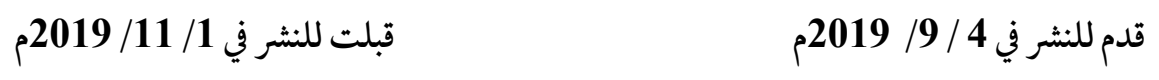

الملخص: إذا كان نقص المعرفة يولد الحوف، فإن البحث عنها يولد الشجاعة، ولذا، فمطلوب من

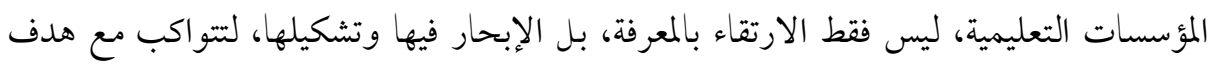

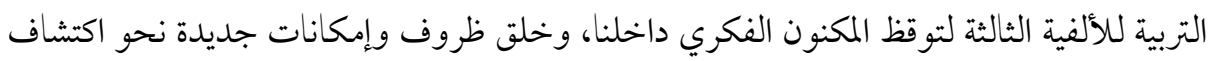

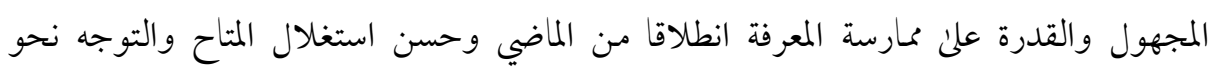

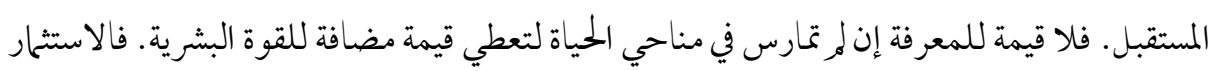

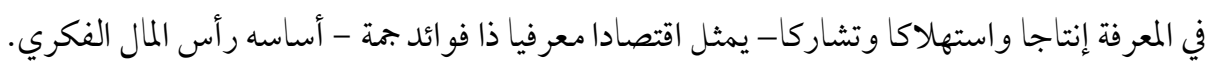

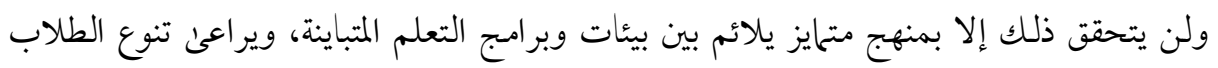

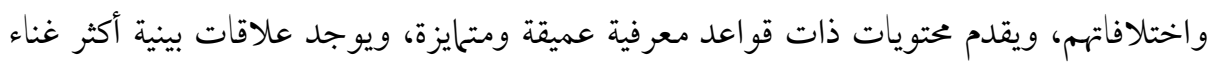

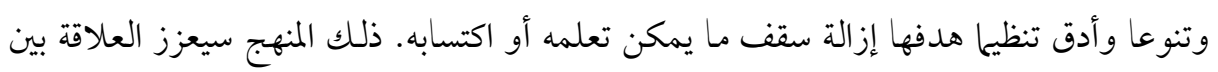

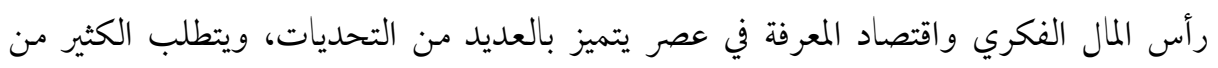

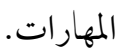
الكلمات الدلالية: المنهج المثليز، الألفية الثالثة، رأس المال الفكري، اقتصاد المعرفة 


\title{
Differentiated curriculum in the third millennium in-between intellectual capital and knowledge economy
}

\author{
Prof. Dr. Taher Mohammad Al-Hadi
}

Professor of Curriculum and Instruction of English Language, College of Education, Suez Canal University, Egypt, talhadi57@gmail.com

\section{Received in 4 September 2019}

Accepted in 1st November 2019

Abstract: If lack of knowledge creates fear, possessing knowledge creates courage. Therefore, all educational institutions not only have to promote but upward develop knowledge via navigating and (re)formulating it in order to keep pace with the goal of education in the 3rd Millennium awakening the intellectual repertoire inside all of us, creating new conditions and capabilities for discovering the unknown and having the ability to practice knowledge - departing from the past, making full use of what is available and orienting for the future. Knowledge has no value unless it is practiced in all aspects of life in order to provide an added value to the human power. Therefore, investment in knowledge - whether producing, using, or sharing it - constitutes some sort of knowledge economy of immense benefits based on the intellectual capital. Such processes cannot be carried out, but by a differentiated curriculum compromising with various educational programs and varied, different learning contexts, considering individual differences, providing varied contents of deep and differentiated cognitive rules, and finding rich, varied and well-organized interdisciplinary relations aiming at removing the ceiling over what is learnable. The differentiated curriculum will, therefore, cement the relationship between the intellectual capital and knowledge economy in an era that is characterized by many challenges and needs many skills.

Keywords: Differentiated Curriculum, Third Millennium, Intellectual Capital, Knowledge Economy 


\section{مقدمة}

المنهج - لا يقوم في فراغ وهو محكوم بفلسفة المجتمع وثقافته، وتوجهاته نحو المستقبل. وهـو نتاج تفاعل بين أسس ومكونات وعمليات خختلفة - تنتظم فيـه المعرفـة بالحيـاة، والحقـائق بـالخبرات و الرؤين، والمصالح بالقيم والأخلاق، والنظريات بالأداءات والممارسات، والانطباعات بالتفسـيرات و التوقعات بشكل يتكيف مع أهداف ذلك المنهج · ولأن العلـوم الإنسـانية تـتلاطم فيهـا إشـكاليات المفاهيم والمصطلحات، ووجهات النظر والأيدولوجيات والتوجهات، مـا يدفع إلى البحـث عـن دور

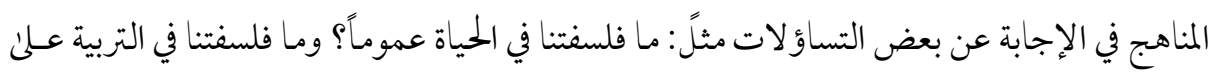
وجه الخصوص؟ وما مو جهات حياتنا؟ وما المعايير التي تقـوم عليهـا أحكامنـا الثقافيـة والأخلاقيـة والاجتماعية؟ وما أساليب حياتنا التي قد تتوافق أو تتعارض مع هذه المعايي؟؟ وما هو الإطار الفكري الذي تصاغ في ضوئه تلك الفلسفات والموجهات وتلك المعايير؟! وهل يمكن للمنـاهج - في الألفيـة الثالثة - أن تقدم ماعجزت عن فعله في الألفيات السابقة؟ (طاهر الهادي:2011).

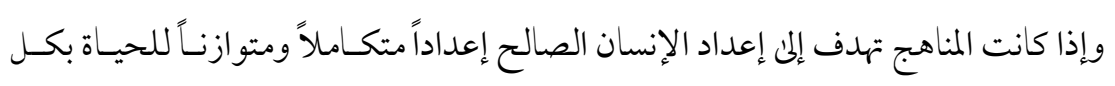

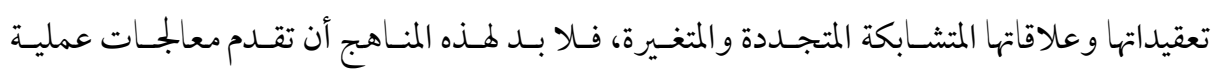
للتساؤلات سالفة الذكر، وتعيد فهم التجارب الإنسانية والانتقال بها من العمق التاريخي إلى حالة من

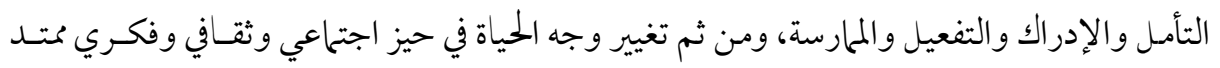
يشمل الذات والآخر أينها كان ووقتما كان.

و إذا كان المنهج - كما يركئ الهادي (2011) - في تعريفه المستحدث في ضـوء مــدخل الـنظم علن أنه "نظام متكامل من الحقائق والمعايير والقيم الإنسانية الثابتـة والمعـارف والخـبرات والمهارات الإنسانية المتغيرة التي تقدمها أي مؤسسة تربوية - إلى المتعلمين فيها أو تهيؤها لهم أو ترشدهم إليها كل حسب قدر اته وإمكانياته بغرض إحداث تعلم أو تعديل أو تغيير في سلو كهم وتحقيق نموهم نموا شاملا متكاملا بها يتو افق مع غايات التربية في مجتمعهم." (ص35)، فإن بناء المنهج في تنظيم معسين -

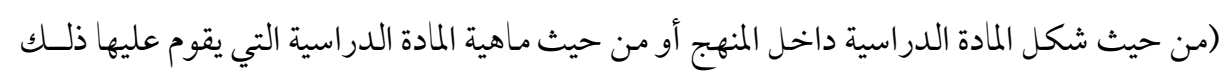


المنهج أو من حيث شكل المنهج وتنظيمه، أو من حيث ما يركـز عليـه المـنهج أو مسن حيـث الوجـود المباشر / غير المباشر للمنهج أو من حيث الفئة التي يستهدفها المنهج أو مسن حيـث السلطة/ المؤسســة التي قامت بوضع المنهج أو تطبقه...) يعد من الإشكاليات الكبيرة بين أنصار كل تنظيم. بل وتتبـاين الصراعات بين من يساندون التنظيم المنطقي للمادة الدراسية والتنظيم النفسي ها وبين من يعلـون مـن

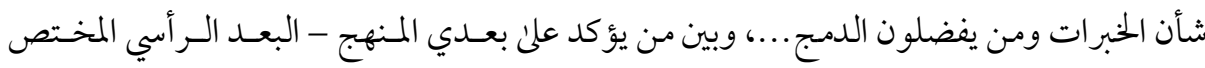
بترتيب محتوئ المنهج علن امتداد الزمن والبعد الأفقي المختص بترتيب مكونات محتوىن المنهج جنباً إلى جنب في تتابع منطقي وتكامل موضوعي. الأمر الذي يدعو إلى وجود منهج متمايز. فكل منهج يمثـل

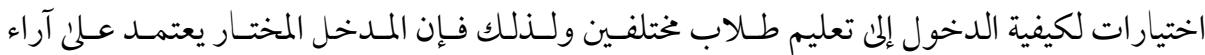
ومسلمات الذين يقومون بإعداد المنهج ·ويقصد بالمسلمات: الفلسفات ووجهات النظر وتهتم بالأسئلة الآتية: كيف يحدث التعلم وكيف يتم تسهيله؟ مـا الأهداف التي تستحق الإعداد و التنفيذ؟ ما المحتون الأكثر أهمية و كيف يتم تنظيمه؟ كيف يجب تقييم التقدم التربوي؟ مـاذا يجـب أن تكـــ العلاقـة بـين

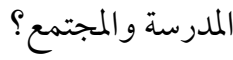
أولا: المنهج المتحايز

ماهية المنهج المتمايز

من الطبيعي والعقلاني والموضوعي ألا يكون الجميع - حتى وإن مروا بتجارب مشابهة، وعاشوا حياة واحدة لديهم نفس القناعات والسلوكيات وأحيزة فكرية وأشراط أفعال وأعمال وأحجيات متماثلة. فالقناعات المختلفة تتمايز عن بعضها البعض من خلال النوع المختلف للأفعال التي تأتي بها إلى حيز الوجود، والسلوكيات غالبا لا تقوم إلا علن قناعات، والأحيزة الفكرية تحددها أيدولوجيات معينة، وأما الأفعال والأعحال فمرهونة بأهداف لها حجيتها من أجل إيجاد إدراكات

و انطلاقا من رؤية هابرماز (نقلا عن هاو، 2015:188) في أن " علام الحياة هو عالم من المعايير والقيم سابق علن النمذجة وقد تخلق وتمايز إلى نظام بجتمعي فريد، وهو كنظام فرعي ينقسم 
أيضا إلى مزيد من الأنظمة الفرعية، وهو يشجع ضروبا معينة من التكامل والاندماج الاجتماعيين وضروبا معينة من التمثل الثقافي، وضرويا محددة من نمط الشخصية"، فإنه يكون لزاما على المنهج الذي هو من الحياة وللحياة أن يكون متمايز ا يستمد مقوماته من استنهاض الامكانية التحررية المتأصلة في الحياة وتفعيلها. فالتمايز يبقي المجتمع ويحافظ عليه، ولا يمكن التوصل إليه إلا بالحوار وخلق فكر جديد يوازن بين متطلبات النظام التعليمي وغائياته وبين الحاجات المتباينة المتزايدة لآحاد المتعلمين ومشكلاتهم الملحة. و التمايز "يعد إطارا أو فلسفة لمساعدة الطلاب من كل المستويات على تفعيل قدراتهم الكامنة" (منرو Munro - نقلا عن تايلر Taylor ، 2017:ص 55)، ولتحقيق هذا، فإنه يتمركز حول اكتساب المعرفة ومعالجتها وتكوينها وتفسير ها بالإضافة علن عقلنة الأفكار، ويشمل هذا التمايز إعداد مواد تعليمية وإجراءات تقييم ومنهج متجدد، وهو أساس لتحقيق الحاجات الفردية لكل المتعلمين،

$$
\text { ولغض النظر عن قدراتهم ودرجة التحصيل الحالية عندهم. }
$$

يساعد في زيادة دافعية المتعلمين وتحصيلهم الدراسي، وتشارك أكبر بين الطلاب متشابهي وتهي نهره

القدرات (تايلر 2017:Taylor، هيرتبيرج-ديفيس:2009 Hertberg-Davis).

يتناول عدم التجانس heterogeneity والتحديات المختلفة داخل الفصل الدراسي (ويست

وويست:2016 West \& West).

يعد أسلوبا للتسهيل علن المتعلمين في أن يكونوا أفرادا متفردينunique، ويعطيهم الفرصة لتعلم نموذجي (بيتي:2004 Petty).

يشجع المعلمين علن تعديل وتكييف ممارستهم للتدريس والتعلم والتقييم (فيكرمان

.(2009 Fickerman:

يسمح للطلاب بالتقدم في تعلمهم بخطو pace يناسبهم بغض النظر عن معارفهم ومهار اتهم وأفهامهم السابقة (وو :2013 Wu). 
يمكن أن يقدم منصة للتجديد والتأمل المستمر تعزيزا لعمليتي التعليم والتعلم التي لن

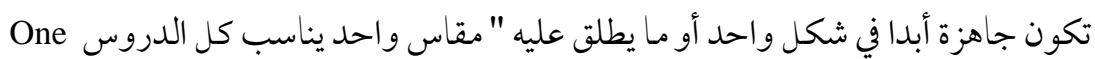
size fits all lessons وبناء عليه، ظهرت عدة تعريفات للمنهج المتمايز، فيرئ بيج وفالي Page \& Valli (1990) أن المنهج المتهايز يركز علن قيام المتعلم بخلق المعنى من خبرات متحايزة داخل الفصل الـدراسي، اسـتجابة محايدة للفروق الفردية بين المتعلمين - والتي قد يكون لها تأثير سلبي عند إهماها. بينما في نظر مكهنري وجايلز McHenery \& Giles (2016)، المنهج المتمايز هـو برنـامـج تعلـم يشـبع الرغبـات الأكاديميـة

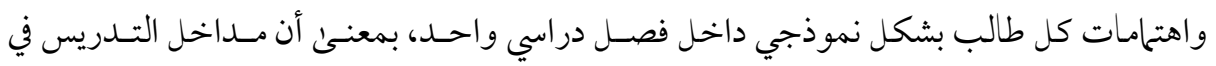
المنهج تكون مرنة لكي يكون محتوئ المنهج قابلا للهضم digestiblexible ويثير التحدي للقـدرات الكامنة داخل كل طالب بذاته لتحقيق تعلم متمايز وصو لا إلى العدالـةequality ، و العدالـة هنـا تعنسي إعطاء فرص متساوية للتعلم وليس التدريس للجميع بنفس الطريقة تمامـا بتحام. وقـــ يشـير الباحثـان

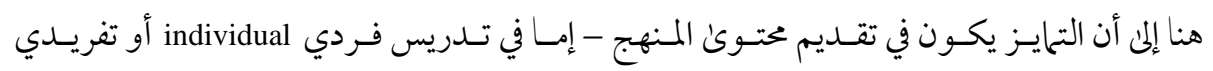

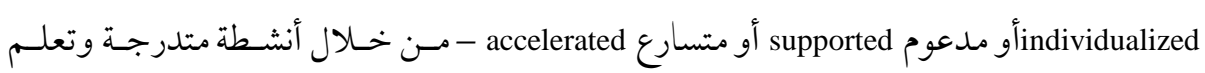

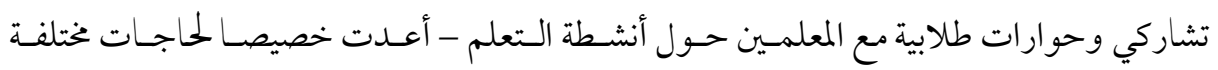
ومتمايزة لأن الطلاب ليسوا سو اء بسواء، ولكنهم خختلفون ولا يز الون مختلفين.

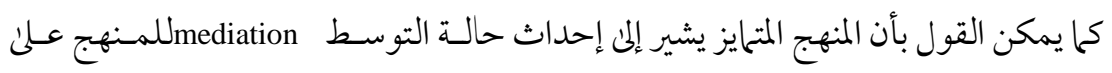

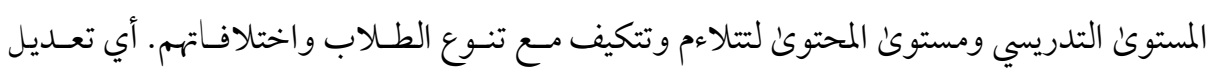
وضبط: بيئة التعليم والتعلم، وأساليب التعليم والتعلم، ومو اد دعم عمليتي التعلـيم و الـتعلم التي

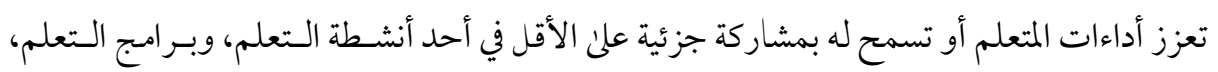
والتقييم (طاهر الهادي: 2017). 


\section{سمات المنهج المتحايز من حيث غائيات المنهج}

من إحدى وظائف المنهج عموما - "أنه أداة الحفاظ على البنـى المعرفيـة للعلـوم المختلفـة بــا فيها من حقائق ومفاهيم ومبادئ وقوانين ونظريات ونقل الخـبرات في المجـالات المختلفــة وتقييمهـا و تصنيفها و / أو إنتاج معرفة جديدة وتوظيفها توظيفا فاعلا في تلك المجالات و الحفاظ عـلن الثوابـت الإنسانية والقيم والمعتقدات كل في بيئتها ومجتمعها ومن ثم بناء اتجاهات لبناء ذاتية ثقافية متميزة عـن

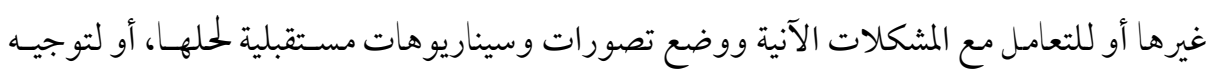
المجتمعات نحو تحقيق أهداف محددة في سياق بنية اجتهاعية مستقرة سالمة مع نفسها محافظة عسلن ذاتها ومتو اصلة مع الآخر" (طاهر الهادي، 2011)، فيكـون مسن وظـائف وسـات المـنهج المتهايـز كيفيـة التعامـل مع القو اعد المنطقية والموضوعية عند بحث رسوخ الآراء أو إلغـاء اللايقـين، أو عنـد تنـاول قناعات راسخة وسلوكيات مقاومة للو اقع أو إدراكات جديدة تحاول ترسيخ السلوك المتزعزع. وكما ينص تقرير شئون المجتمع العالمي (1995) أن "الاهتحام بتحقيق الانصـاف لا يسـاوي

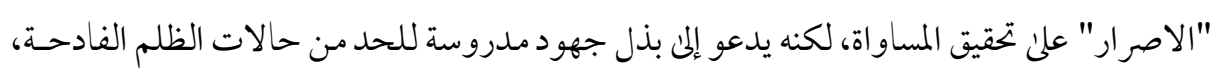

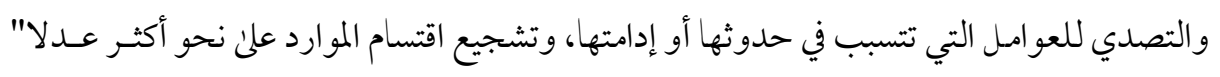

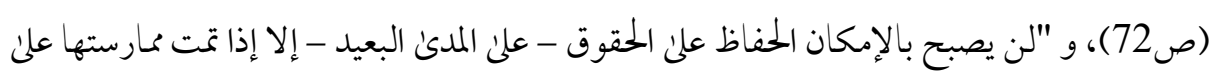

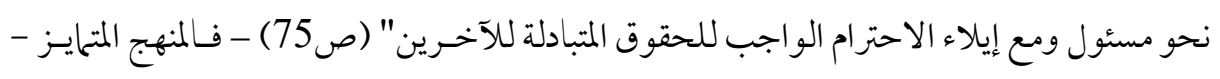
إذا - يراعئ شئون الجميع ولصالح الجميع، وهو ضد الانفصالية في التعامل والاهتحام. فالمنهج المتحايز

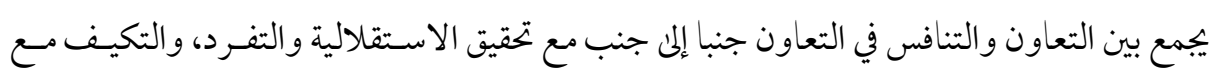
الجماعة، مع الاستجابة للمطالب والفروق الفردية للمتعلمين.

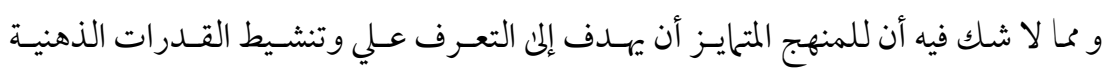
العديدة والمتنوعة القابعة داخلنا ومعرفة طريقة تفكيرنا وبنيان عقلنا وكيفية التغلب علي العجز الملازم

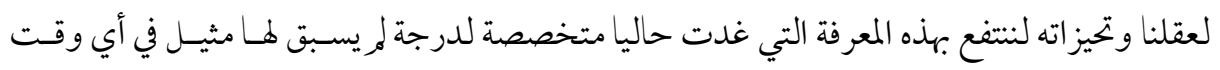


مضي، تأكيدا بأن " الإنسان صاحب عقل جـوال، وإرادة قويـة، وقابليـة عظيمـة للـتعلم و الارتفــاع والجهل و السقوط... دائم التذبذب، مشبوب بالعاطفة... و العواطف تسمو وتهبط - حسبـ سـلوك الانسان وتوجهاته" (نعحان السامرائي: 2001)، و تأكيدا على المبدأ القائل بأن أهم وظيفة للمنهج هي بناء الانسان: الجسمى فيه وعاء، والروح حارس، والعقل دليل، فإن تمـايز ذلـك المـنهج يكــون مر اعيـا النمو المتكامل المتوازن للطاقات والمو اهب و الاستعدادات والقدرات وتفعيـل المهــارات، بــا يضـمن الازدواج الأبدي للطبيعة الانسانية - جسم وروح وعقل - ولكن في شروط زمانية ومكانية مناسـبة. ولقد ذهب هابرماز (نقلا عن ألن هاو، 2015: ص 256) إلى أن "العقـل هـو مـا يمكنتـامـن فهـم الو اقع ورؤية حقيقة الأشياء في سياقاتها المختلفة والمتبدلة. وعليه، فإن المعرفة ليست سـياقية وحسـب بل كلية أيضا، وليست سكونية بل عرضة للتنقيح وإعادة النظر بتغير الأحوال".

$$
\text { من حيث أهداف المنهج }
$$

المناهج وهي أداة التربية يمكن أن تحافظ علن أعمدة التربية الأربعة التي أعلنها جاك ديلور في تقريره إلى اللجنة الدولية عن التربية للقرن الحادي والعشرين المسمى "التعلم: ذلك الكنـز الكـامن". وهدف هذه الأعمدة هي أن الشخص يتعلم ليعرف ويتعلم ليعمل ويتعلم العيش مع الآخـر ويـتعلم ليكون. ولن يكون ذلك كذلك إلا بإقامة التوازن بين الحوار مع الذات الذي هو "العمل على مراجعة

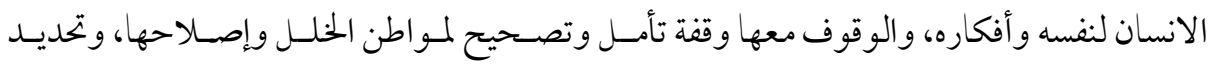

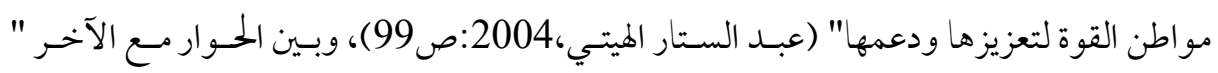
للتعرف علن ما يهدف إليه من حيث طبيعة علاقته بالآخرين ورسم مسـتقبل أفضـل لجميـع شـوب العالم ضمن دائرة التفاهم المشترك، وعدم التجاوز على الخصوصية الدينية والأخلاقية، بـا يطلق عليـه اليوم المحافظة علنى الهوية الثقافية للأمم"(ص 145"، ويكون ذلك في جو من الحرية المنضبطة وتحمـل

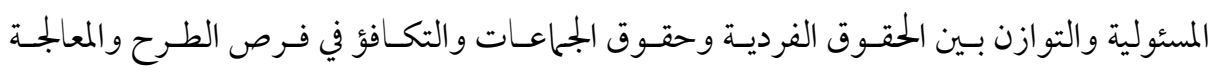
والمراجعات النقدية تبعا لقو اعد وشروط و أحكام عامة يشترك فيها الجميع. 
ومن وجهة نظر نفسية، يركن الباحث أن التمايز قد يرتبط بتصـنيف الـذات - إذ أن " الأفـراد الذين يصنفون ويدركون علن أنهم أفراد غختلفون في سياق ما، يمكن أن يعاد تصنيفهم ويدركوا كأفراد

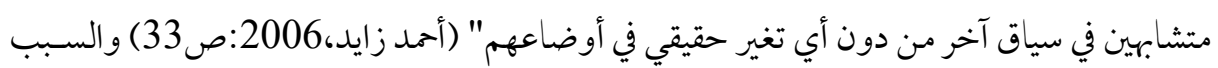
في ذلك قد يكون مقارنة الذات بالآخر في نفس السياق الاجتماعي، والتغير في إدراك الذات ومـن ثـمـ تغير السلوك بين أفراد الجلماعة الواحدة أو المجموعات الأخرى كاستجابات وجدانية إيجابية.

\section{من حيث الملامح التربوية والتعليمية للمنهج}

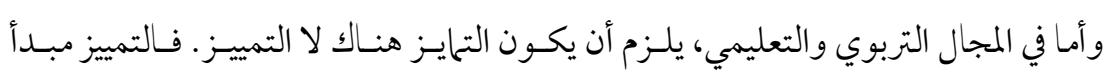
تسلطي تعسفي يعنى بتغييب مبدأ تكافؤ الفرص وحرمان البعض من حقوق مشروعة ومثبتة تاريخيـا

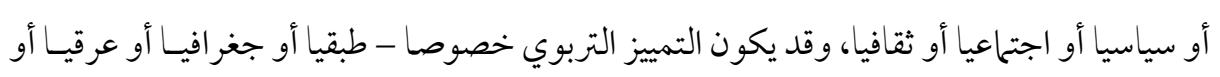

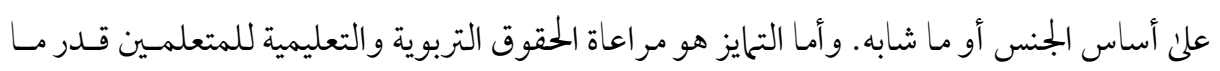
تتيحه لهم قدراتهم واهتماماتهم وحاجاتهم لتحقيق أهدافهم.

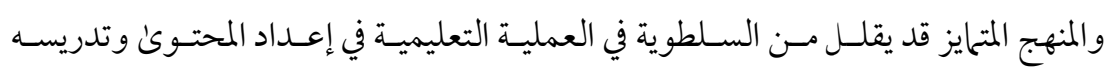
وتقويمه بعيدا عن البيئات التي غالبا ما تغرس في طلابها "عادة حفظ المواد الدراسية مـن دون تفكير

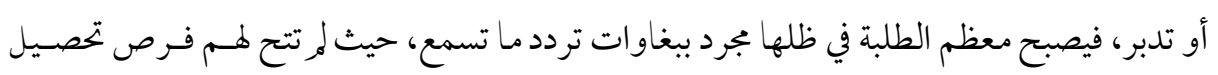
المعارف والتجارب بأنفسهم من خلال الاحتكاك بالو اقع، أو الاطلاع علن المصادر المختلفة للمعرفة،

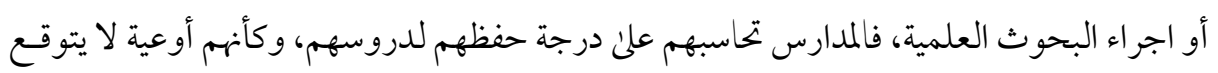
منها إلا احتو اء بعض المعلومات، بدلا من أن يكونو اعقو لا تهتدي إلى المعلومات أو تتفاعل معهـا، أو

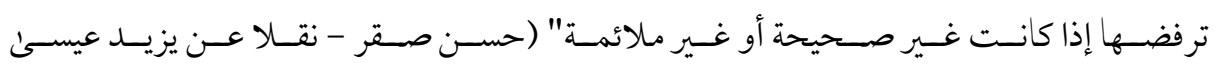
السورطي، (2009:19).

ويعتقد الباحث أن التمايز في المنهج قد يراد به تنوع النظريات التي يقوم عليها المنهج في أربعة

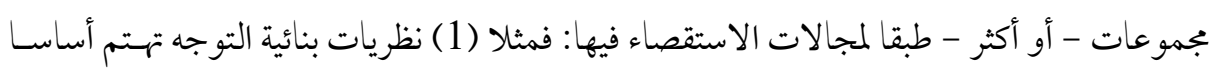
بتحليل مكو نات المـنهج والعلاقـات المتداخلــة بينهـا، وتميـل هـذه النظريـات إلى أن تكـون وصـفية 
وتفصيلية وشار حة في هدفها، و (2) نظريات قيمية التوجه و تهتم أساسـا بتحليـل القـيم والمسـلمات التي انطلق فيهاصانعوا المنهج وما أنتجوه وتميل هذه النظريـات إلى أن تكـون نقديـة بطبيعتـه، و (3) نظريات يوجهها المحتوىن: و تهتم في الأساس بتحديد محتون المنهج وتميل لأن تكون توجيهية إرشادية في طبيعته، و (4) نظريات توجهها العمليات وتهتم أساسا بوصف كيف يتم تطوير المنهج أو التوصية بكيف يجب أن يتم تطويره وبعض من هذه النظريات وصفي في طبيعته بينما الآخر توجيهي إرشـادي (طاهر الهادي، 2016). (ط)

وإذا جاز الاعتماد علن محتوئ واحد يقدم لجميع الطلاب، فليس من الجائز أو المقبـول تربويـا تقديمه بطريقة تدريس واحدة، فإن ذلك يبعث علن الملل، ويقلل الدافعية، وتضيع معها فرص بعض الطلاب للاستفادة وإعمال التفكير وانطلاق العقول إلى فضاءات أرحب وأوسع. وعليه، فـإن المـنهج المتمايز قد يكون في نظرنا منهجا تو افقيا في تفعيله وتقييم مخرجاته. ويرئ يزيد السـورطي (2009) أن

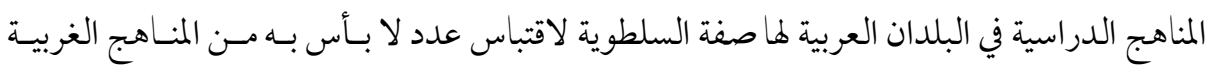
وترجمته، أو اعتهاد المناهج التي صاغتها النظم التعليمية في البلدان العربية تركز علن المعرفـة بــلا مـن الطالب، ومحتويات تلك المناهج - كما ذكر يوسف (نقلا عن يزيد السورطي) - "لا تلبي احتياجـات

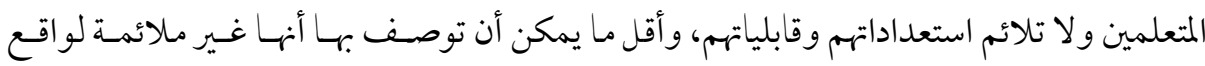

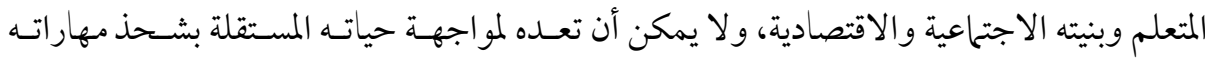

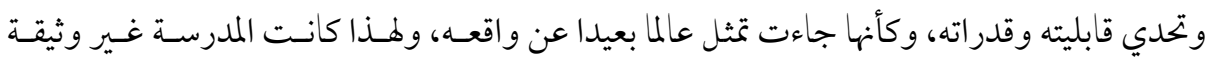
بالحياة" (ص24)، مع العلم أن المنهج المدرسي من الحياة وللحياة - كما أكد طاهر الهادي (2017). ويرئ الباحث أنه يمكن أن يكون التمايز هو الـتخلص مسن السـلطوية في المنـاهـج الدراسـية تركيزا علن قطبي العملية التعليمية: المعلم والمتعلمين، ويقصد بذلك عدم حرمان المعلم من الاشتراك في تخطيط و تصميم المنهج وتقويمه وتطويره فضلا عن تدريسه، بدلا من الإذعان والقبول لكل ما فيها من أراء وقناعات شخصية وانتهاءات وأيدولوجيات لو اضعيها. و إذا كـان ذلـك كـذلك، فمـن حـق المتعلمين أيضا أن يكون لهم سهم في ذلك لأنهم الطرف الأول في العملية التعليمية وتتمحسور حـولهم

\section{http://dx.doi.org/10.29009/ijres.3.1.2}


وحول حاجاتهم وميو لهم وأهدافهم، "فالمناهج يجب أن تكون وسيلة لخدمة الفرد والمجتمع، لا غايـة يطوع في سبيلها الطلاب" (يزيد السورطي،2009:27).

وقد يكون تمايز المنهج في التركيز علن أساسيات يشترك فيهـا جميـع المتعلمـين وتكـون قابلـة

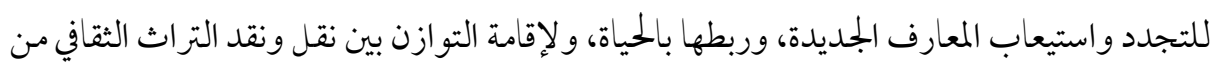
جهة وبين التوجهات المستقبلية وبدائلها من جهة أخرىن - أصـالة ومعـاصرة، بـين المعرفـة وتعلمهـا وممار ستها وبين مر اقبتها وتنظيمها وإدارتها وتشاركها وتوليد معرفة أخرى من جهة ثانية، بين الانفتاح علن الثقافات الأخرىن والاحتكاك بها وبين الاستفادة منها مع الحفاظ علنى الهويـة الوطنيـة و الانتـاء الوطني دون تقوقع من الذات أو هيمنة من الأخر، بين تحقيق أهـداف المـنهج في وقايـة المجتمـع مـن المخاطر والمشكلات و العمل علئ تحقيق سـيادته و حفـظ أمنـه وسـلامته واستقر اره وبـين ورفاهيتـهـ وسعادته في بيئة تناغمية.

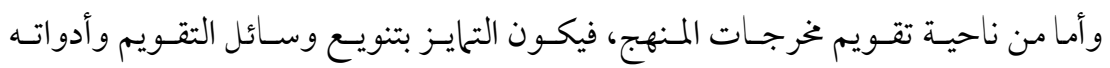

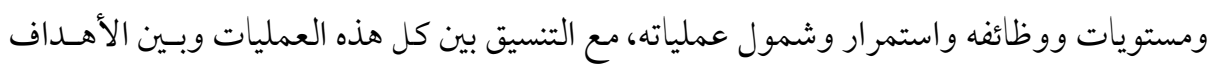
المحددة سلفا وبين غائيات التربية في المجتمع.

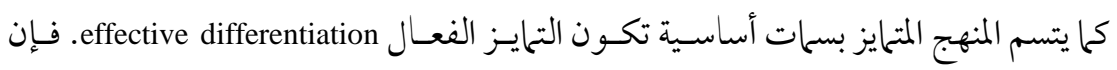
فهمها والالنزام بها ييسر عمل المعلم ونجاح المتعلم في فصل سريع الاستجابة responsive وهي: الفصل المتمايز يتسم بالمرونة.

تمايز التدريس ينبع وينطلق من التقييم الفعال والمستمر لحاجات المتعلمين. التجميع المرن يساعد في التأكد من وصول الطالب لعدد كبير متنوع من فرص التعلم وترتيبات العمل work arrangements في سياقات وييئات تعليمية متنوعة، كل الطلاب يعملون بشكل متسق في الأشطة التي تتسم بالتسلية واتساع الحيل وتتميز بالاقتراح مع ترتيبات تعلم خختلفة بشكل متساو مع الآخرين وتتيح فرصا متساوية للفهم والمهارات الضرورية لهم ولا يفترض التمايز مهام مختلفة لكل متعلم ولكن مرونة في درجة 
تعقيد المهمة task complexity والتعبير عن أنماط التعلم التي ييد معه المتعلمون التعلم

$$
\text { تطابقاملائحا معظم الوقت. }
$$

الطلاب والمعلمون متشاركون في عملية التعلم: بين معلم مؤهل تأهيلا واضحا يشخص ويصف العلاج لحاجات التعلم ويسهل التعلم ويبرع في إعداد فهم فعال وطلاب مشاركين حيويين يحملون معلومات محورية عما يناسبهم والأساليب المفضلة لديهم في التعلم، وباختيار اتهم ويأكثر استقلالية.

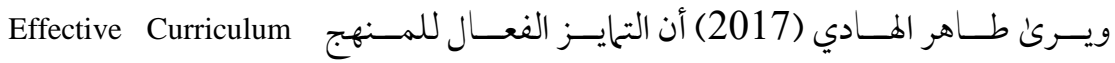
Differentiation يساعد آحاد المتعلمين علن تعويض ما سببته العوائق الداخلية والعوائق الخارجية. يسمح للمتعلم باستخدام المهارات الحالية مع تعزيز تطوير مهارات أخرىن جديدة في ذات

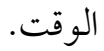
يمنع حدوث تنافر مين مهار لdissonance لفصل معين. يقلل مستوئ المعلومات المجردة ليجعل المحتوى مرتبطا بالسياق التدريسي الحلاي أو البيئة الحالية للمتعلم ولحياته في المستقبل كذلك. يخلق تناغما وانسجاما بarmony أسلوب التعلم لدىن المتعلمين وأسلوب التدريسي لدني المعلمين. يشكل أساسا لتعديل customizingبرامج التعلم حسب الطلب. (صص262-63). ولتفعيل التمايز، - كما يعتقد الباحث - هناك بعض الملامح التي تحتاج إلى المرونة ومنها: أن تكون الأنشطة مرنة بالحد الذي يسمح لعدد أكبر من المتعلمين بالمشاركة. يمكن أن يكون السياق التدريسي مرتبطا بحاجات المتعلمين. يمكن إعطاء أو تخصيص وقت أكبر لتقييم المهام او تنفيذها. 


$$
\text { طرق وأساليب التقييم يمكن أن تكون مرنة لتشمل جو انب متعددة. }
$$

يمكن بناء برنامج التعلم لإشباع حاجات متعلمين معينين (موهوبين - متأخرين دراسيا...

$$
\text { الخ }
$$

يمكن تعديل التوقعات تبعا لقدر ات المتعلم ضمن إطار التوقعات العالية.

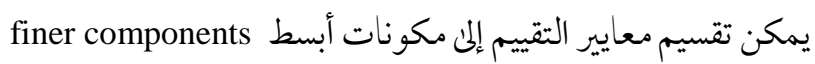
الوقت المخصص لخطة درس يمكن أن تتنوع من نشاط قائم بذاته إلى تدريس فصل دراسي أو تخصيص وقت أكبر إذا لزم الأمر تبعا لحاجات المتعلم، تسريعا أو إبطاء، مع تكامل جوانب التعلم learning areas weightings تخصيص وقت معين لتحقيق خخرجات التعلم وتحديد أوزانها يمكن أن يتنوع عدد وطبيعة برامج التعلم في المدرسة تبعا لمدئ توافر هيئة تدريس ومصادر للتعلم ومعرفة حاجات المتعلمين. مراعاة المرونة في اختيار معايير معينة للتقييم تبعا للحاجات الفردية للمتعلمين اعتمادا على توصية فريق التقييم - في حالة عدم قدرة المتعلم علن تحقيق معايير تخرجه. (الهادي، طاهر، .61-60، 2017 مبادئ يقوم عليها المنهج المتحايز وانطلاقا من أن كل الطلاب يستحقون منهجا غنيا يسمح بمستويات مختلفــة مـن الوضـوح والمباشرة، أو التجريد والتعقيد والموضوعية وتستجيب لحاجاتهم، ولتحقيـق السـات المقترحسة أنفـا، قدم جريجوري وتشابهان Gregory \& Chapman (2002) مبادئ أساسية لتمايز المنهج يجملهـا الباحـث

تقديم المحتوكن المرتبط بقضايا وموضوعات أو مشكلات كبيرة يقوم عليها. تكامل أنظمة متعددة في المجال الواحد من مجالات الدراسة. تقديم خبرات شاملة ومترابطة ذات تعزيز ثنائي داخل إحدى بجالات الدراسة. 


$$
\text { السماح للتعلم العميق لموضوعات ذات اختيار ذاتي داخل إحدى بجالات الدراسة. }
$$

$$
\text { تشجيع تنمية التي تستخدم أساليب ومواد وأشكال جديدة. }
$$

تشجيع المخرجات الطلابية عن طريق استخدام معايير مناسبة ومحددة من خلال أدوات

$$
\text { تقييم ذاتي مقننة ومحكية المرجع. }
$$

وفي نفس السياق، قدمت مدارس أورتنج 2014)Orting Schools عددا آخـر مـن المبـادئ التي يقوم عليها المنهج المتمايز: دراسة الفروق الفردية كأساس للتخطيط - الفــووق الفرديـة تشكل المنهج - مشاركة الطلاب في وضع الأهداف والمعايير - إتاحة مو ادمتعددة للتعلم - تقديم اختيارات متعددة للطلاب - المعلم يعدل المحتون والعمليـات والمخرجـات استجابة لاستعدادات الطسلاب واهتماماتهم وملفات إنجاز تعلمهم - مراعاة خطو التعلم لدىن خختلف الطـلاب - استخدام معـايير

$$
\begin{aligned}
& \text { متدرجة ومتنوعة - التدريس والتقييم لا ينصلان مع مراعاة المرونة. } \\
& \text { مكونات المنهج المتحايز واستراتيجيات تنفيذه }
\end{aligned}
$$

بالاطلاع علن الأدبيات و الدراسات السابقة (مثل: تيرويـل Terwel:

1996 /1986:Maker تيرويل و ووكر Terwel \& Walker : 2004، فارمر:Guido: 1998، جيو 2016، ويسلي 2014:Wesely جايلز:2016 McHenery \& Giles )، ظهـر للباحـث أن هنـاك ثلاثـة مكونـات لعمليـة تمـايز المـنهج Components of the curriculum differentiation process التخطيط لتمايز نشاط ما ليلائم كaccommodate كل المتعلمين.

كيف يمكن تمايز المحتوى/ السياق التدريسي لكي يكون مرتبطا بالخبرة

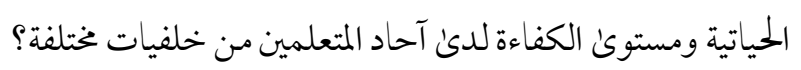

ما التمايزات المطلوب القيام بها للمنهج المقدم أو المزمع تخطيطه؟ وكيف

$$
\text { يمكن تمايز طريقة عرضه و تقديمه؟ }
$$

http://dx.doi.org/10.29009/ijres.3.1.2 
ماذا سيؤخذ في الاعتبار عند تقييم أداء المتعلم في ضوء الأهداف والسياق التدريسي واستراتيجيات جمع وتقييم وتسجيل وكتابة التقارير وبناء على ما سبق، فهناك بعض الأفكار لتطبيق مكونات التمايز:

تمايز المحتوىن، ويكون من خلال: اختيار المحتوى المناسب للقادمين من خلفيات مختلفة، واختيار المحتوكن الملائم لاهتمامـتهم والمؤثر في سلوكياتهم، والتقليل من مستوى التجرد الموجود بالمحتوئ، و وضع مهمة بديلة لمدئ بديل ومطلب مشابه، واستبدال مهمة بمهمة أخرى نختلفة، و تقديم نصوص أو محتوى أكثر صعوبة للمتعلمين الذين هم في حاجة لفرص تعلم أكبر وأوسع، وجعل المهام قصيرة، واختيار الكتب والمهام المرتبطة بثقافة المتعلمين، و تقديم محتوى متنوع يناسب اهتمامات المتعلمين، واستخدام مهمة أخرى خخططة

$$
\text { لتقييم شخرجات أكبر وجو انب أخرى مما تم تخطيط تقويمه. }
$$

تمايز طريقة عرض المحتوىن، ويكون من خلال السماح للمتعلم بتنفيذ المهمة في وقت لاحق، و استخدام أدلة مرشدة للاستذكار، و استخدام المنظلات المصورة graphic organizers، وتوضيح ونمذجة بل واستثارة الاستجابة المتوقعة، واستخدام أنواع متنوعة من المهام التي تربط بين المفاهيم وتوسعها، وإعادة تدريس المحتون إذا كان ذلك ضروريا، واستخدام مواد إضافية، وخلق بيئة تعليمية محفزة يتم فيها تقدير خلفيات الطلاب والاعتراف بها، وتقديم مساعدة فردية لمن هم في حاجة إليها، وتغيير شكل تقديم المهمة التدريسية. تمايز استراتيجيات التقييم، ويكون من خلال تصميم الأنشطة التي تسمح بمكان لأساليب تعلم غختلفة وذكاءات متنوعة، وتشجيع المتعلمين على الربط بين المعاني المقدمة والمفاهيم المختلفة من أجل تحقيق الرضا الذاتي، وتقديم/ توفير فيرص للتعلم المشارك learning، واستخدام أنشطة ذات سرعات و والسماح للمتعلمين بوقت إضافي لإتمام مهامهم، واستخدام التكنولوجيا والمعينات والترتيبات الخاصة بغرض تنفيذ مهام التقييم المطلوبة، الاحتفاظ بملفات الانجاز الخاصة بملاحظة متعلمين معينين والذين 
هم في حاجة لدعم إضافي، وقراءة تعليات الاختبارات بل والاختبارات نفسها، وتقديم أشكال متنوعة من الأسئلة، و اختبار المفاهيم الأساسية تمثل ضرورة، و إعداد تقارير شفوية وأخرى تحريرية، والتركيز علن الجوانب الإيجابية أو مواهب المتعلمين أو مجال ذكاءتهم المرتفعة.

ولأن المنهج المتحايز يشير إلى الحاجة إلى تفصيل بيئات التدريس والممارسات الحادثة فيها لخلق أو إيجاد خبرات تعلم مختلفة لطلاب خختلفين، فإن المنهج المتحايز لا يكون كذلك إلا في ضوء مجموعة عناصر

بيئة التعلم Learning Environment، وهي تلك البيئة المشجعة للطلاب لإظهار قدراتهم في حدها الأقصن، ويجازفون ويبنون معرفة بل ويكتسبون مهارات في بيئة آمنة مرنة تسمح هم بذلك وهذا يشمل أن تكون البيئة متمركزة حول الطالب student-centered - أي encouraging تركز علن اهتمامـاته وأفكاره ومدخلاته، وأن تكون مشجعة للاستقلالية independence منفتحة متشجع علئ قبول أفكار الآخرين وآراءهم قبل تقييمها، وأنت تكون مركبة أي تشتمل على تنوع غني من المصادر والوسائط والأفكار و الطرق والمهام، وأن تتميز بالتحرك السريع أي تشجع علن الحركة من و إلى المجموعات و المقاعد و الفصول والمدارس.

تعديل المحتوى Content Modification وهدف التعديل هو إزالة سقف ما يتم تعلمه، واستخدام قدرات الطلاب من أجل بناء قاعدة معرفية knowledge base أكثر غناء وأكبر abstractness تنوعا وأدق تنظيما. و يسهل القيام بهذا البناء عن طريق تشجيع التجريد الخاص بالمحتوى منتقلا من الحقائق و التعريفات والأوصاف إلى المفاهيم والعلاقات القائمة

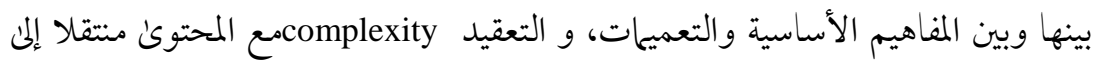
العلاقات البينية المتبادلة بدلا من الاقتصار على العوامل المرتبطة وأخذ كل منها في الاعتبار

\section{http://dx.doi.org/10.29009/ijres.3.1.2}


- كل علن حدة، و التنوع Variety المحتوكن ليمتد فيها وراء المحتوكن المقدم في البرنامج العادي، ودراسة الناس Study of peopleبما فيها دراسة الأفراد أو الشعوب، وكيف يكون الشتون

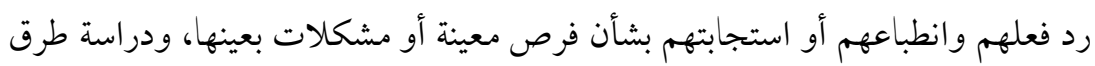
الاستقصاء Study of methods of inquiry فيها الاجراءات التي يستخدمها الحبراء

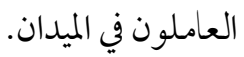
تعديل العملية: Process modification، فالهدف منها هو تعزيز الابداع والمهارات المعرفية

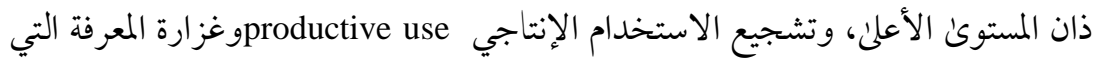

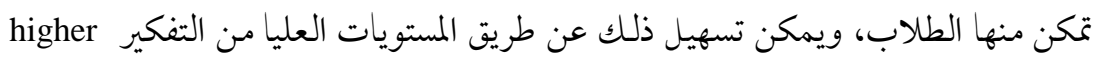

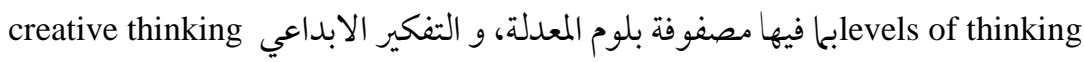

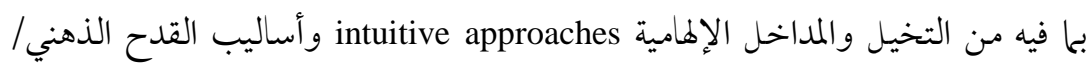

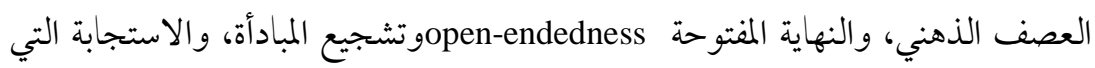

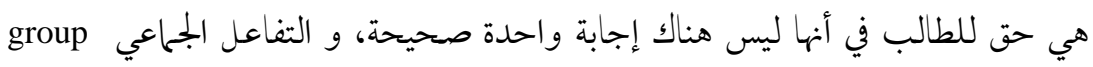

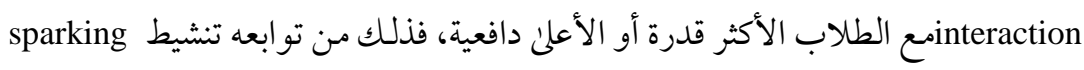
بعضهم البعض في بعض المهام علن أساس تنافي أو تعاوني، والخطو أو السرعة المتغيرة وvariable pacing من المهارات الدنيا للتفكير إلى المهارات العليا في التفكير.

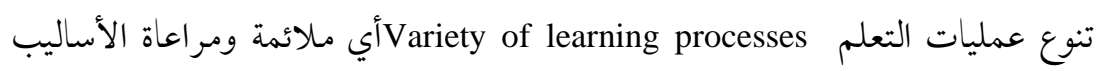

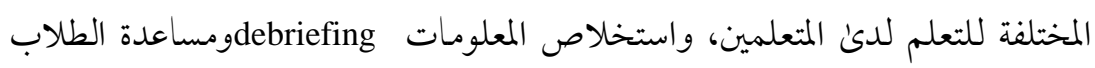

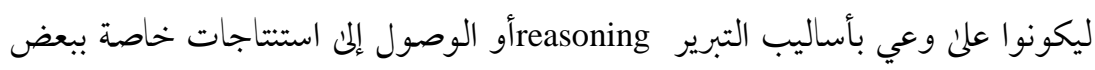
الأسئلة والمشكلات، بل ويكونون قادرين علن القيام بتلك الأساليب، وحرية الاختيار

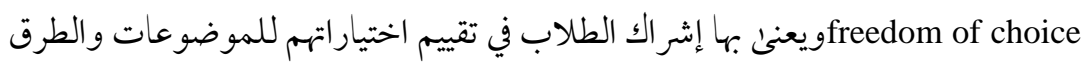

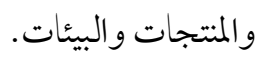


تعديل المتتج Product modification والهدف هو تسهيل الفرص للطلاب الموهوبين لإنتاج منتج يعكس قدراتهم الكامنة. ويمكن تشجيع ذلك عن طريق إدخال مشكلات real مقيقية real problems مرتبطة بحياة الطلاب وأنشطتهم، و جماهير حقيقية audiences real بعينها أو بجتمع معين أو مجموعة ذات اهتحام خاص، ومواعيد استحقاق حقيقية deadlines original manipulation transformations للمعلومات بدلا من الانكفاء علن القديم أو الاندفاع إلى الوراء regurgitation، و التقويم المناسب للمنتج وذلك باستخدام معايير العاله الحقيقي الموضوعة من ذي قبل والملائمة لثثل هذه المنتجات.

ومن الملائم أيضا أن تكون هناك بعض الاستراتيجيات الإدارية لتنفيذ المنهج المتمايز التي غالبا

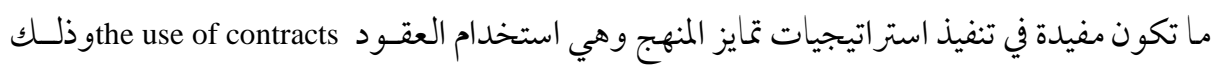

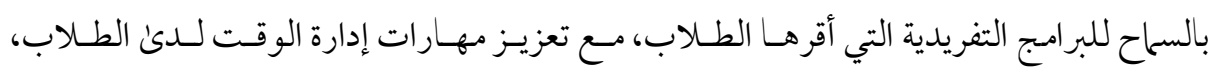

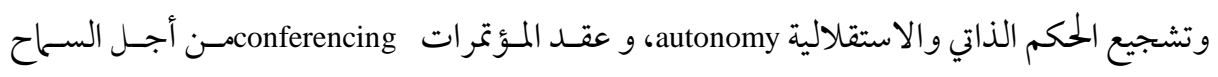
لتخصيص مساحة للتفاوض حول المنهج ومراجعتـه مـن قبـل الطـلاب، و اسـتراتيجيات التجميـع ووتركز علن تجميع العقول المتشابهة"grouping strategies ولأن من المؤكد أنه لا يتشابه متعلمان تمام التتشابه، فلك منهلا استعداداته وقدر اته واختيار اته لحصول علن المعرفة وإدر اك المفاهيم، ولكي يكون المنهج متمايزا، فعلن المعلم - منفذ المنهج - أن يعدل ويكيف: ماسيتعلمه الطلاب (المحتوي (content)، وكيف يتعلم الطلاب المحتوئ (العملية Process)، وكيف يظهر الطلاب تعلمجم كمحصلة نهائية (المخرجات Product) قدم فريند Friend وكوك Cook (نقلا عن طاهر الهادي، 2017) عددا من المداخل للتـدريس التشاركيCO-teaching - كأحد نماذج التدريس المتحايز - التي تقدم أساليب لمعلمين اثنين للعمل معـا 
داخل الفصل. وهذه المداخل هي: معلم يـدرس ومعلــم يـدعم One teach, one Support، التـدريس

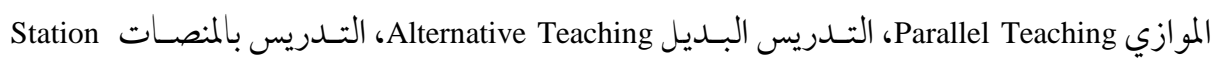
Teaching Team و التدريس بالفريقTeaching المدخل الأول: معلم يدرس ومعلم يدعم One teach ,One: support وفي هذا النموذج المعلم الأول - أيا كان هو - عليه المسئولية الأولى والأساسية للتخطيط والتدريس بينما المعلم الآخر يتجول داخل الفصل يساعد الطلاب ويلاحظ سلوكيات وآداءات معينة، فمثلا أحدهما يشرح والآخر يقدم المواد التعليمية مع ملاحظة السلوكيات غير المرئية للمer. المدخل الثاني: التدريس الموازي Parallel Teaching: وفي هذا المدخل، يقوم المعلم والمعلم الطالب يخططون سويا plan jointly ويقسمون الفصل نصفين لتدريس نفس المعلومات في نفس الوقت، مع السماح للمعلمين للعمل مع مجموعات أصغر وتنصيف splitting الطلاب طبقا لرغباتهم. - مبر. المدخل الثالث: التدريس البديل alternative teaching وفي هذا الشكل من التدريس، يدير أحد المعلمين معظم الحصة بينما المعلم الآخر يعمل علن مجموعة صغيرة داخل أو خارج الفصل، لمتابعة تكليف متأخر catch up on a missed assignment، أو أعمال علاجية أو

$$
\text { لأغراض التقيم أو لتدريس المهارات الاجتماعية. }
$$

المدخل الرابع: التدريس بالمنصات station teaching: وفي هذا المدخل يقوم كلا المعلمين بتقسيم المحتوى التدريسي، ويتحمل كل منها مسئولية تخطيط وتدريس الجزء الحخاص به. ويتم تقسيم الفصل إلى مراكز تدريسية متنوعة teaching centers، فلمعلم والطالب المعلم يكونان علن منصات معينة، بينها المنصات الأخرى يديرها الطلاب أو بمن يعاونه وذلك لك بشكل مستقل، تحديدا للمسؤولية وقدرة المعلمين علن تغطية محتوئ تعليمي أكبر في فترات زمنية أقصر. 
المدخل الخامس: التدريس بالفريق Team Teaching: كل المعلمين طبقا هذا المدخل مسئولون عن التخطيط، ويتشاركون في التدريس لكل الطلاب. ويتم تدريس الدروس من قبل كلا المعلمين اللذين يشاركون في المحادثة والحوار مشاركة فعالة وليس في المحاضرة وذلك من أجل تشجيع المناقشة من جانب الطلاب فكلا المعلمين يتشاركان وبفاعلية في أداء الدرس وإدارة النظام داخل الحصة، ويمكن لهذا المدخل أن يكون فاعلا أكثر مع معلم الفصل الأساسي و الطالب المعلم أو طالبين معلمين معا. ثانيا: الألفية الثالثة السمات والخصائص تعد مهارات الألفية الثالثة أو ما تعرف بمهارات القرن الحادي والعشرين من متطلبات الجيل الجديد من الطلاب في مجتمع المعلومات. ويتألف إطار تلك المتطلبات من المهارات الحياتيـة والمهنيـة، ومهارات التعلم والابتكار، وحسن التعامل مع وسائل الاعـلام، ومهـارات التكنولوجيـا وغيرهـا. و هذا يتطلب إنشاء أنظمة دعم لتطوير مهارات القرن الواحد و العشرين وجود أنظمة قياسية وتقييمية

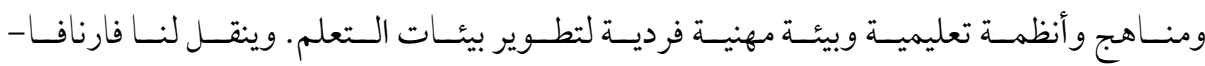
ماروتشاو Varnava-Marouchou (2004) - نقلا عن اليونسكو أن حاجات ومتطلبات بجتمـع القــرن الحادي و العشرين تكمن في مثلث زواياه المعرفة وتكنولوجيا المعلومات والتعليم وتمشيا مع تلك المتطلبات، طرح تـوزان Tausan (2003) مـا توصـل إليـه المجتمعـون مـن الاتحاد الأوروبي في استوكهوله 2001 من تحديد ثلاثة أهداف اسـتراتيجية تستهدف نظـم التكـوين التعليمي و المهني في أوروبا تحقيقا لمبدأ التعلم مدئ الحياة، وهذه الأهداف تتمثل في: (1) تحسين جودة وفعالية نظم التكوين التعليمي والمهني، (2) تيسير إتاحة نظم التكوين التعليمي والمهني لكل النـاس، the European فتح نظم التكوين التعليمي والمهني للجميع. وعليه، حددت المفوضية الأوروبيـيـية Commission

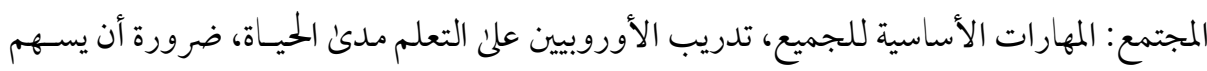

\section{http://dx.doi.org/10.29009/ijres.3.1.2}


التعلم في النمو الاقتصادي المستدام، ضرورة استجابة التعلم للتغيرات داخـل المجتمعـات، المدرســـ

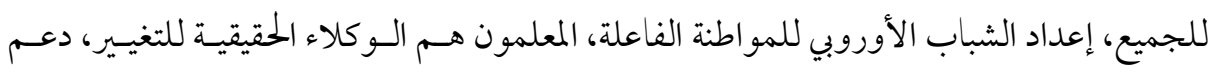
المجتمعات المدرسي نحو التطور ـ و تفعيلا لذلك الأمر، وتو الت ردود الأفعال ومنها ما قام به بايوليتي (2018) بإطلاق ما أسماه التعليم للألفية الثالثة (PTM) Pedagogy for the Third Millennium)، وهي طريقة تعليمية قام بتطبيقها في المشارع الخيرية والتربوية والتدريبية - قوميا وعالميا - وتختص بـالتعليم والاتصال كفاية وكفاءة للأطفال و البالغين سواء بسو اء.

ومن السمات التي أجمع عليها الباحثون أن (1) التعلم للجميع Education for all، وطبقا لهذا المبدأ فلن يتخلف طفل و احد عن ركب التعليم بعد اليوم ويصير التعليم متاحسا للجميـع دون قيـود

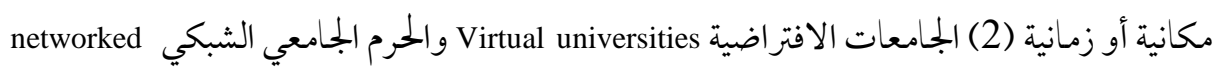
campus وتتمتع بحرم جامعي تربطه شبكات الكترونية و (3) والقضـايا الخضر _اء Green issues وتركز عسلن

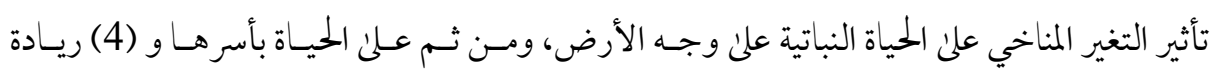

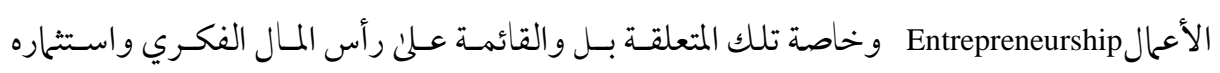
اقتصاديا لتحقيق ميزة تنافسية.

$$
\text { مهارات التعلم في القرن الحادي والعشرين }
$$

لقد أجمع غالبية الدارسين و المفكرين و العلماء مثل تشين (Chen, 2008) وفيشر (Fisher, 2014) وجيبسون كايويت (Gibson-Cayoyette, 2010) أن مهارات القرن الحادي و العشر-ين تتمثـل في أربـع والع

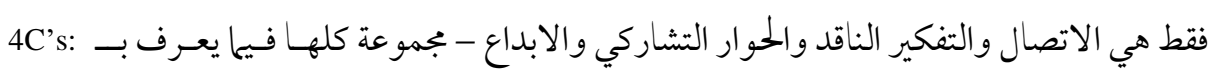
(Ozanne, communication, critical thinking, collaborative dialog and creativity (2013 تركئ أن مهارات القرن الحادي والعشرين ثثانيـة هي: الاتصـالية Communication والحوسـبة

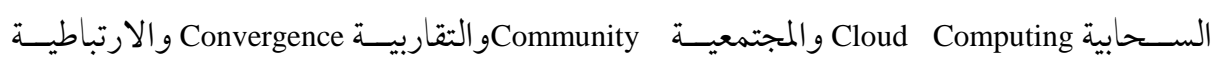


Connectedness و السياقية Contextualization و المجانية Cost و التشاورية Collaboration بجموعة 8C's ف وهناك من تناول مهار ات القرن الحادي و العشرين (مثل زوك Zook (2018) مؤكدا علن أنها يجتاج إليها طلاب اليوم وتساعدهم في وظائفهم في عصر المعلوماتية والانترنت - بل لمسـايرة الخطـو المستنير لعالم اليوم. ثم قسمها إلى تصنيفات ثلاث: (1) مهارات التعلم Learning skills هي لتعليم الطلاب العمليات العقلية المطلوبة للتكيف مع بيئة عمل حديثة وتحسين العيش فيهـا، ويطلـق عليهـا وتشمل التفكير الناقد (إيجاد حلول للمشكلات) والابــاع (التفكـير خـارج الصـندوق) والتشـارك (العمل مع الآخرين) والتو اصل (التحدث مع الآخرين). (2) مهارات التنور Literacy skills تركز علن كيف يستطيع الطلاب الكشف عن الحقائق ونشرــمنافـذها والتكنولوجيـا القابعـة خلفهـا، مـع التأكيد علن تحديد المصادر الموثوق فيها وفرز المعلومات التي تقوم علن الحقائق من المعلومات المغلوطة

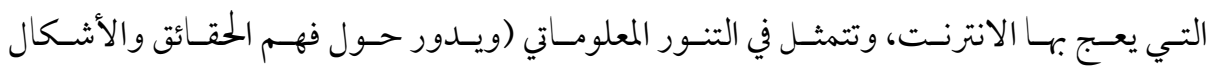
و الاحصائيات والبيانات) الذي ينقسم إلى التنور الوسائطي (ويدور حول فهم الطـرق والمنافـذ التي تبث وتنشر المعلومات)، والتنور التكنولوجي (فهم اللآلات التي تجعل عصر المعلوماتية ممكنا) و (3)

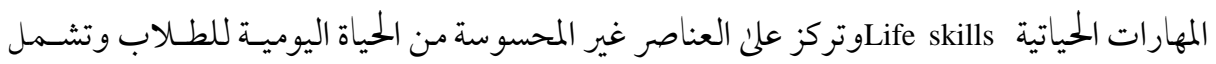

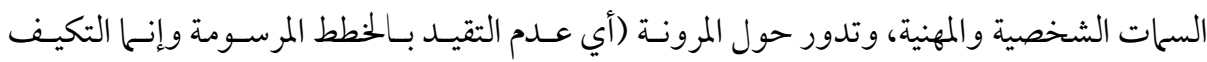
للموقف حسب الضرورة والحاجة)، و القيادة (بتحفيز الفريق لتحقيق الهدف المرصود له)، و المبادرة (أي قيام الفرد بالبدء في المشاريع والاستراتيجيات والخطط من تلقاء نفسه)، و الانتاجية (بالإبقاء على الفعالية في أي وقت تحدث فيه مشتتات عن الهدف)، و المهارات الاجتماعيـة (أي الالتقـاء بـالآخرين وإنشاء شبكات تو اصل بغرض المنفعة المتبادلة ). ومن الباحثين من تناول مهارات الألفية الثالثة ورصــها في أربعـة محساور: أسـاليب التفكـير

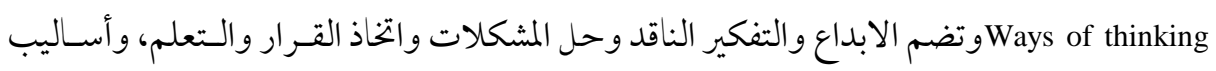
العمل Ways of working وتتضمن التو اصل والتشارك، وأدوات العمل Tools for working وتشـمل 
Skills for living in the الاتصالات والمعلومات والتور المعلوماتي، ومهارات الحياة في العساهروتضسم world المو اطنة المهارات الحياتية والوظيفية والمسئولية الشخصية والمجتمعية. وهناك من زعم بأن هناك أثني عشرة مهارة ضرورية لطلاب اليوم وبدونها لن يكونوا قادرين علن المشاركة بشك ناجح في الاقتصاد العالمي، ولن يكونو ا معدين بشكل ملائم لأن يلتحقو ا بالجامعة

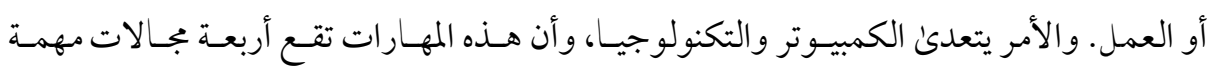
للتطوير والتنمية وهي: (1) التشارك وعمل الفريق، و (2) الابداع والخيال، و (3) التفكير الناقـد، و

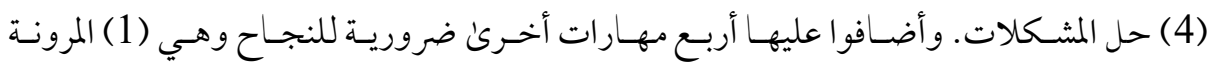
والتكيف، و(2) الوعي الكوكبي والثقافي، و(3) التنور المعلوماتي، و(4) القيـادة. ثـم أفــدوا جانبـا

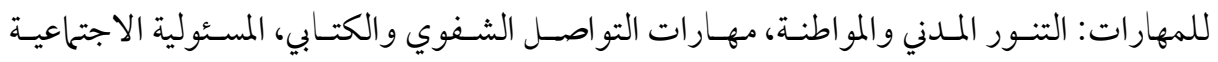

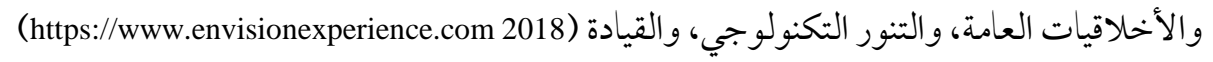
ومن جانبهم، قـدم فاضـل وآخــرون .Fadel et al (2015) المهـارات المطلـوب تو افرهـا في المتعلم بالقرن الحادي والعشرين، وقسموها إلى (1) المهارات المعرفيـة Knowledge (مـا نعرفهـ ومــا نفهمه) وتكون هذه المعرفة بينية، نمطية كالرياضيات وحديثـة كريـادة الأعـال وموضـوعية كـالتنور العالمي، (2) المهارات Skills(كيف نسـتخدم ونـارس مـا نعرفـه) وتضـم الابــاع و التفكـير الناقـــ و التو اصل و التشارك، (3) الشخصية Character(كيف نتصرف ونندمج في العـالم) تشـمل التعقـل و حب الاستطلاع والشجاعة والاصرار والأخلاقيات و القيادة. وكل هذه المحاور تدور في فلك ما بعد التعلم (كيف نتأمل ونتكيف للمستجدات) أي إعمال مهارات ما وراء المعرفة وصو لا إلى نمـو نـاذج

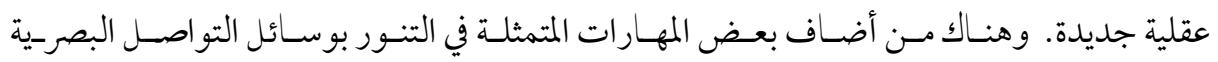
والكفايات الالكترونية والكفايات النفسية والوجدانية. وعلن صـعيد جديـد، قــدم بـراون Brown Navigationism كنظريـة تعلـم جديدة تتناول القضايا التي خلفتها تكنولوجيا الاتصالات والمعلومات، واعتبرها من أهـم المهـارات المطلوبة للتعلم في الألفية الثالثة، وهدفها هو الانتقال لما وراء المبادئ البنيوية في التعلم الشبكي. ولأن 
التعلم في السابق قد ركز علن إنتاج المعرفة وتكوين المعاني، فإن الابحارية تهتم بتقييم مصادر المعرفة،

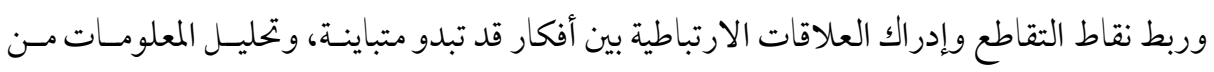

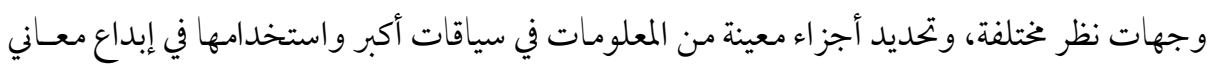

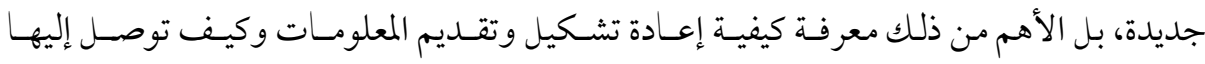

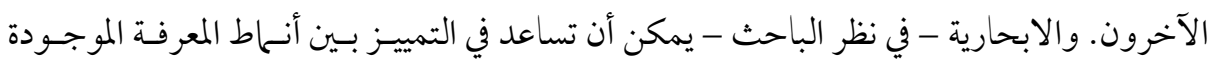

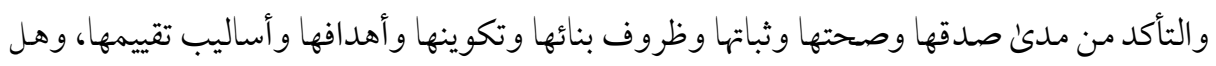

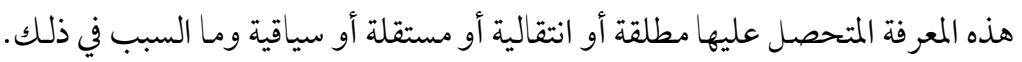

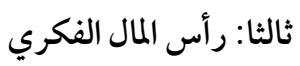

المفهوم

يمكن القول بأن التفكير هو المكون الخام لرأس المـال الفكـري، وهـو " تـنفس العقـل، وإن

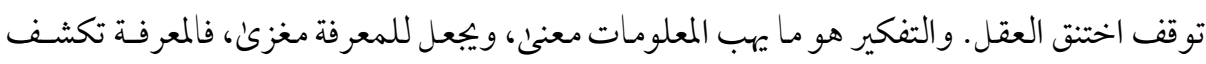

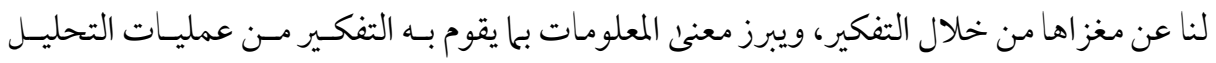

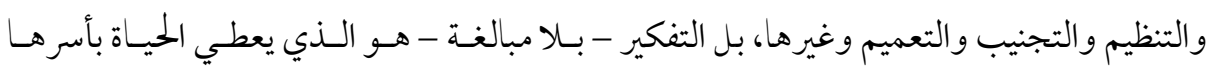

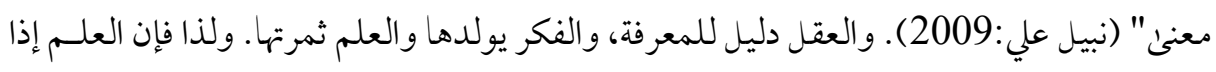

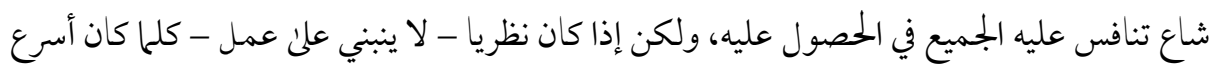
في النسيان

وإذا كانت الحضارة بحاجة إلمد دين، وأن حياتها أو موتها يتوقفان علن ذلك - كما قـال برنسارد

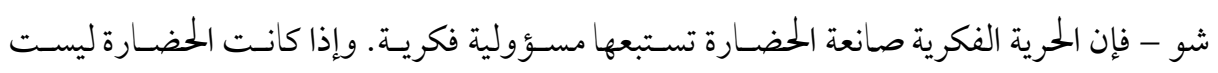

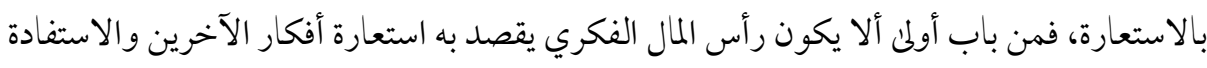

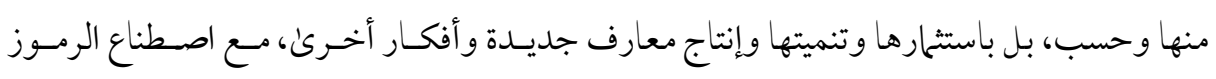

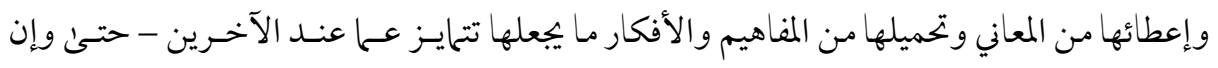

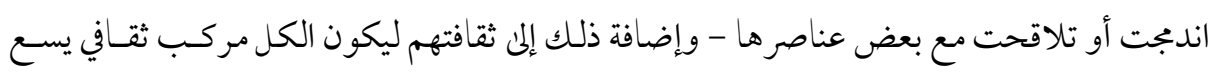

http://dx.doi.org/10.29009/ijres.3.1.2 
الجميع دون تعصب الذي يعد اتجاها سلبيا نحو الآخـرين - بمكوناتـه الـثلاث: المعـرفي والسـلوكي والوجداني، و صوره المتعددة وتفسيراته المختلفة.

حتى في الخمسينات وما قبلها، يؤكد جون ديوي (2001) أن " التفكير في الرأسمال، كـان في حدود مشاريع تبدو اليوم صغيرة وتافهة، ولم يكن لـيحلم أحسـ بـأن وقتـا ههـذا سـيجئ، تبلـغ فيـه

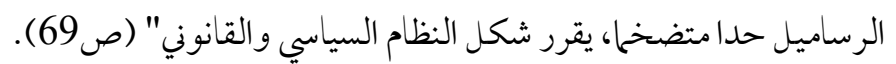

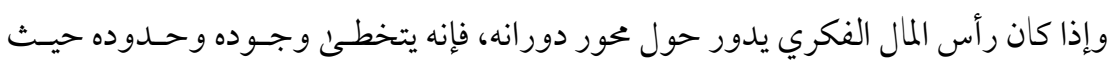
تلتقي فيه المتناقضات ويتم التـأليف بينهـا لتحقيـق تطـوره وتنميتـه، وهـو مـا يطلـق عليـهـ التفاعـل

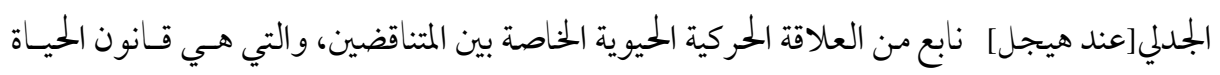
الرائعة (يحي الرخاوي، 1997: 91). و رأس المال الفكري معين لا ينضب، و تفجـره الآراء المتباينـة و التحليلات المتغايرة والنظرات المتقلبة، التي تمثل الطاقة الكامنة لانطلاقه. ومن البديهي أن صـاحب رأس المال الفكري لا يتنفع بفكره وحده، بل لمجتمعه أو لمجتمعات أخرى فيسه نصسيب. ومسن الخطـأ

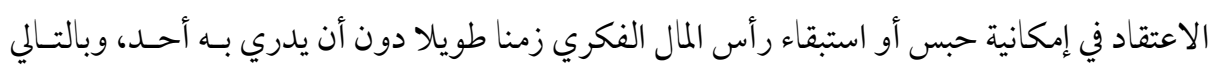

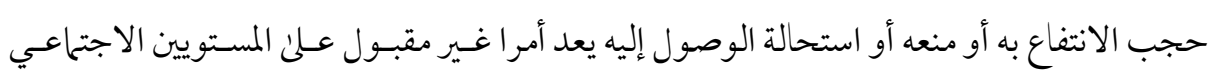
والانساني.

ولقد تعددت تعريفات رأس المال الفكري - من وجهات نظر مختلفة، فهو: كما تراه راوية حسن (نقلا عن منى خليفة، 2012) هو المعرفة التي يمكـن تحويلهـا إلى أربـاح حقيقية تحقق ميزة تنافسية. ويكون ذلك من خلال إجـراءات معينـة مثـل توفيرمنـاخ إيجـابي يسـاعد الأفراد علن اكتساب المعرفة وتيسير الوصول إليها وتحفيزهم علن تعلم واكتسـاب مهـا رات جديـدة، بالإضـافة إلى التوثيـق الشـامل والمـنظم لكافــة العمليـات الفكريــة وتحويـلـ واسـتثمار الاقتراحسات و الابتكارات كمنتج لرأس المال الفكري إلى قيمة سوقية. ورأس الملال الفكري - في نظر إميـل شـنودة

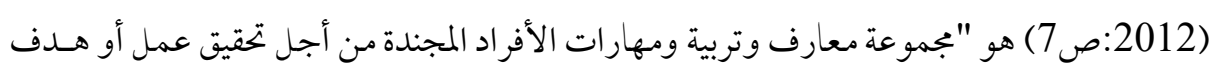

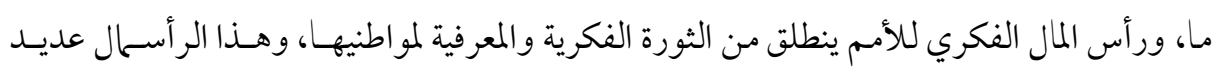


الأوجه، فهو يتشكل من المعرفة الصريحة والمعرفة الضمنية كالمهارات والتجـارب والكفايـات"، بيـنما هو "امتلاك المعرفة والخبرة التطبيقية والتكنولوجيا التنظيمية... والمهارات المهنيـة التي تسـاعد عسلن وجود حافة تنافسية، أو هو أحد المصادر التنافسية لكل الأعمال، كما أنه يستحث التجديـد و الابتكـار المؤديان إلى توليد الثروة" (ستارفيك و مـار Starvic \& Marr ، 2016:6). ولرأس المال الفكري تصنيفات متعددة. فقد قدم ستارفيك و مـار \& (2016)Starvic \& Marr بروه تتمثل في: (1) رأس المال البشري Human Capital والذي هو عبارة عن المعارف والمهارات والخبرات التي يتمتع بها الأفراد، وقد تكون متفـردة في في قـدرتها و قوتهـا وإبـداعها و مرونتهـا وتسـامعها

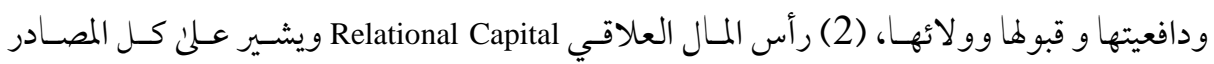
المرتبطــة بالعلاقـات الخـارجيـة، ويضـم رأس المـال البشر-ي ورأس المـال البنيـوي، (3) رأس المـال

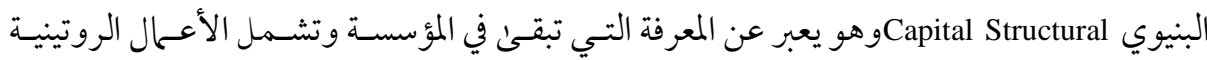
التنظيمية و الاجراءات والنظم والثقافات وقو اعد البيانات بـا فيها خدمات التوثيق و الملكيـة الفكريـة وأصول البنية التحتية. Infrastructure assets.

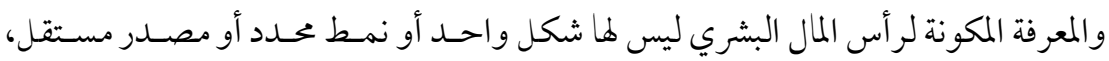
فالمعرفة لا تكون في أي وقت محايدة، فهي تتطور تبعا للقوة المحلددة لهـا، وهـي متـواترة بـين الأفـراد و الجلماعات، كما أنها تخضع لعمليات الاجترار، ولها طـابع الديناميكيـة لتشكلها وتحوهـا مـن خـلال الحوار وعمليات تداو هلا عند نشرها أو استخدامها. وعما إ1ا كانت المعرفة ضمنية (في كونها شخصسية ومعقدة ولا يمكـن البـوح بهـا أو ملاحظتهـا ونتـاج خـبرة و لا يمكـن تعلمهـا) أو صريحـة (ســل ملاحظتها ومستقلة وبسيطة وتقوم علن الحقائق كما يمكن تعلمهـا)- ، متأصـلة (مترسـخة الجـذور في مفاهيم وأطر لا تقاس وتكون ملكية خالصة لجماعة من البشر المهمشين والفقراء في الوقت نفسـه) أو

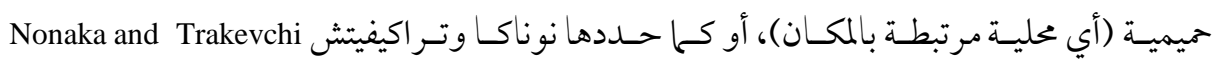
(1995) موغلة في العقل (أي معرفة فردية مجردة تعتمد عـلن مهـارات الفـرد في اسـتيعاب المفــاهيم وادراك النظريات - أي صريحة)، أو متجسدة (أي تقوم علن الخهبرة الشخصسية والتـدريب والملمارسـة 
الفعليـة الموجهـة أي ضـمنية) أو رمزيـة (تشـترك فيهـا الهيئات والمنظطات والجمعيـات العلميـة أو

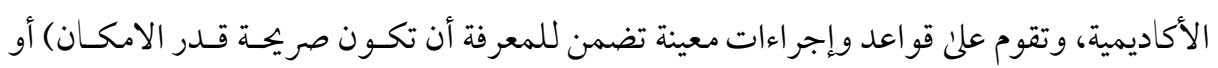

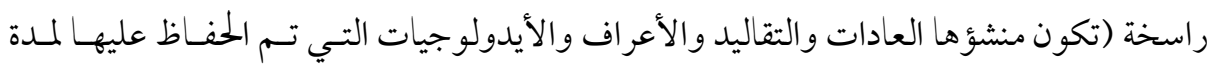

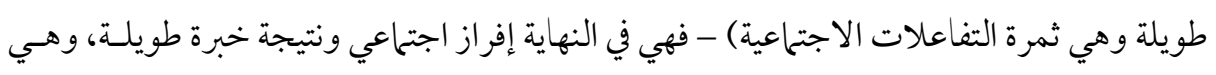

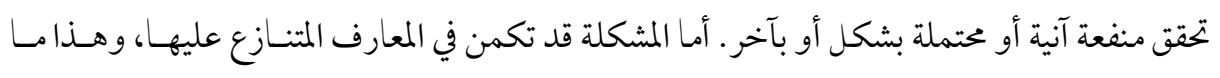
يتناوله الباحث بشيء من التفصيل.

\section{Contested knowledge المعارف المتنازع عليها} ويرئ الباحث أن التنازع قد يكون علين المعارف و مرده إلمى الاعتقاد من أحسد أطراف الحسوار

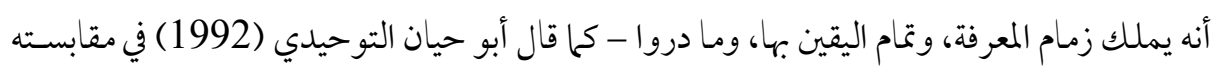

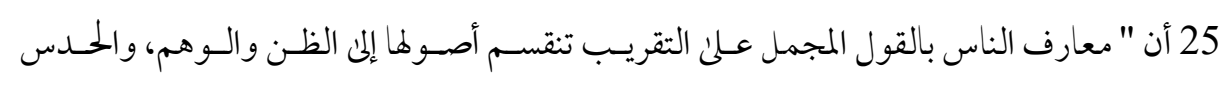

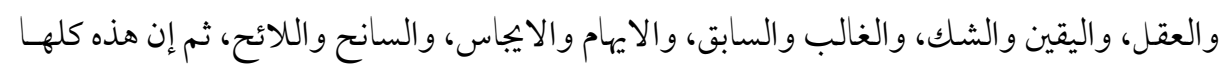

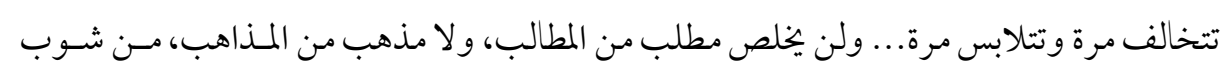

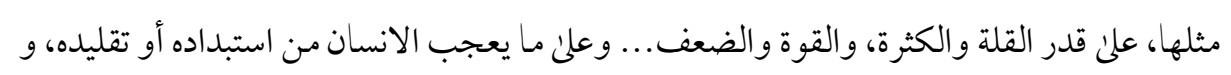

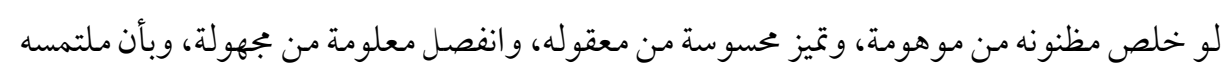

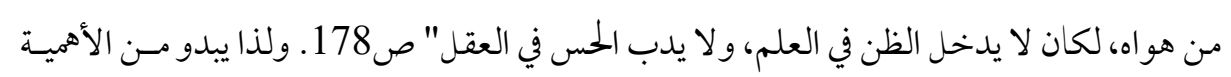

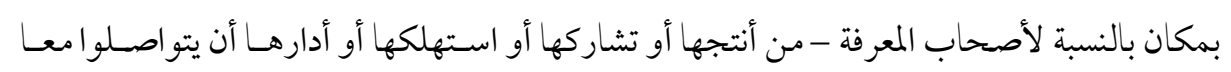

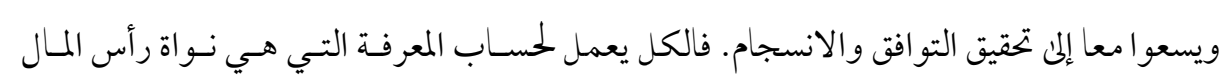

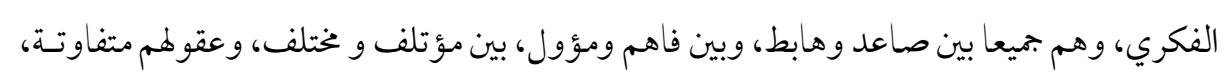

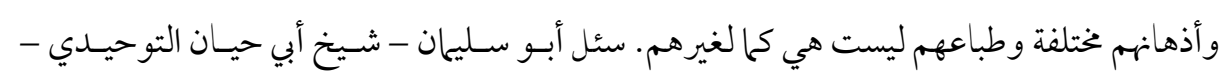

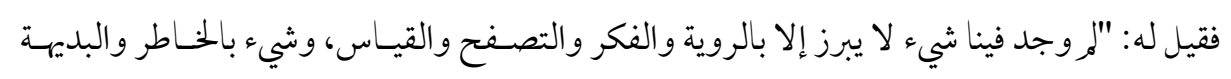

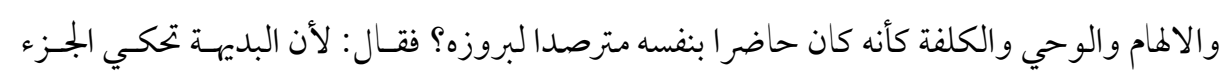

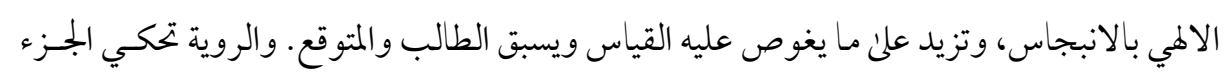


البشري، وكذلك الفكر والتتبع والاستمداد والتوقع، فمن أجلأ انقسام الإنسان بـين شيء ينبعـث بـــ مشتاقا إلى مطلوبة، وبي شيء يبعثه شائقا إلى مطلوبة، ما وجب أن يكون له روية، وهي به، وبديهة هي

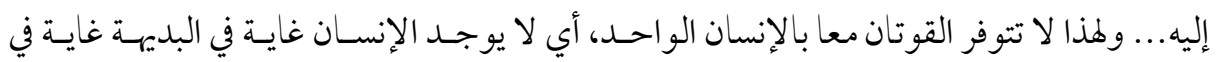
الروية، لأن إحدى القوتين إذا اشتعلت قمعت الأخرىن وحاجزتها عن بلـوغ الغايـة القصـوىن" (أبـو حيان التوحيدي،1992:138). ومن المعارف المتنازع عليها كون التمايز أسلوبا technique في التدريس يقوم المعلمون بتطبيقه

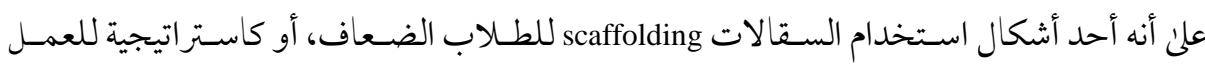
الجحاعي للطلاب الموهوبين، أو هو تكتيك tactic لتحقيق الشمولية inclusivity في التدريس، بينما هو في اعتقاد البعض قيام المعلم باستخدام خبراته ومهار اته في تعـديل وتكييـف الـدروس إشـباع حاجـات التعلم المتنوعة لدى الطلاب (تايلر Taylor: 2017) . حتى أن العوامل المؤثرة في التمايز متنازع عليهـا أيضا. في حين يؤكد البعض على أنها متعلقة بالمدخل القائم علن الطلاب في عمليتي التعلـيم والـتعلم (مثل توملنسون2001:Tomlinson)، ير اه آخرون أن الطبقة الاجتماعية و الخلفية الاجتحاعية والثقافية والجنس والثقافة لهـا دخـل في ذلـك (مثـل طومسـن:Thomsen 2012)، حتــ أن الطبيعـة المتأصـلة

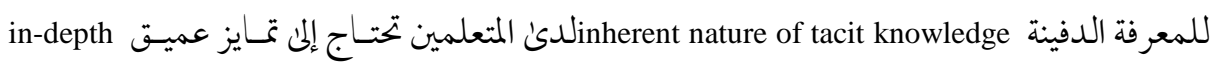
differentiation لفهم الطلاب (وو 2013 ).

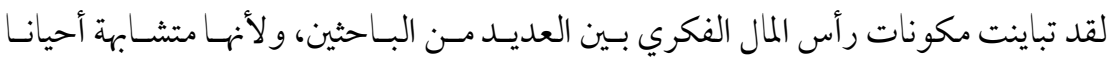
ومتغايرة أحيانا أخرىن، فسيقتصر الباحث علن بعض مـا استعرضـه لـين(2018) Lin في بحثـه منهـا:

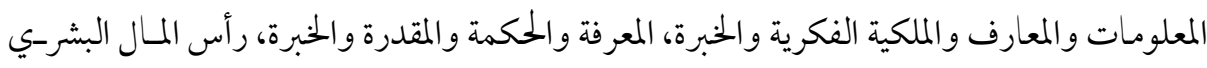
ورأس المال السوقي ورأس المال العملياتي ورأس المال المتجدد، ولكل منها تفصيلات أوردها لين Lin في البحث. تحديات تواجه رأس المال الفكري 
يعتقد الباحث أن هناك بعض التحديات التي تواجه رأس المال الفكر من زوايا ختلفــة. فـلي

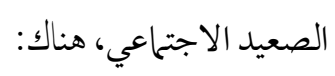

التنشئة الاجتماعية القائمة علن التعصب المعرفي في امتلاك الحقيقة المطلقة وثبات الموروث وجود هويات اجتماعية تتسم بالانغلاق الفكري والتمحور حول الذات صاحبة الأفكار

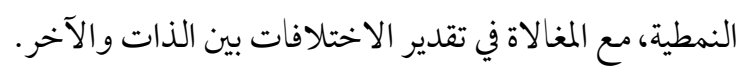

ممارسة السلطوية بين أفراد المجتمع الو احد - بين أهل الفكر وأهل السياسة، بين القيات الفيادات

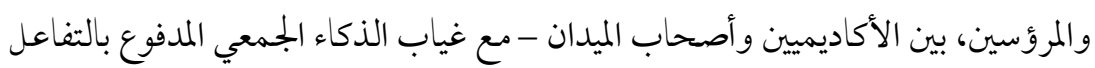

بين الجميع من أجل زيادة معدل إنتاج المعرفة وتجاولها واستهلاكها.

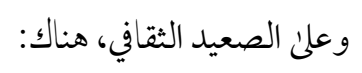

الاستعلاء الثقافي لبعض الشعوب والأيدولوجيات الثقافية، أو وجود علاقة شبقية

$$
\text { بمعارف الماضي والتردد في عيش الحاضر والخوف والقلق الدائم من المستقبل. }
$$

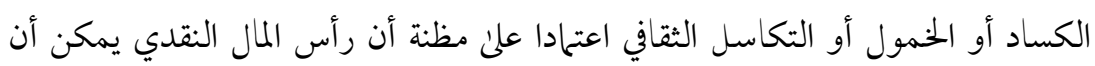

$$
\text { يصنع أو يشتري رأس مال فكري. }
$$

رفض ثقافة الآخر حتىل لو كان ذلك رالك الآخر هو مصدر الاشعاع الحضاري حاليا في ظل

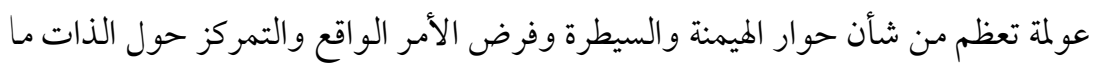

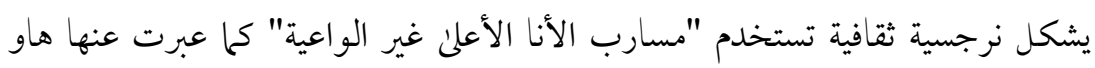

$$
\text { (2015)، أو وجودما يمكن تسميته بالاستبعاد المتبادل. }
$$

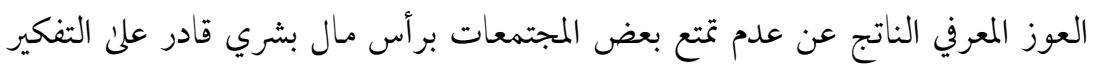

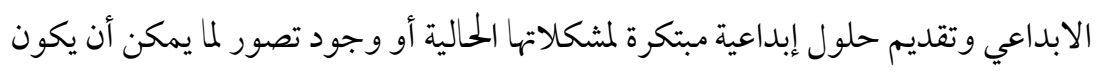

$$
\text { عليه مستقبلها. }
$$

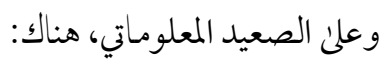


الفيضان المعلوماتي المنهمر والدائم الذي يفرض انتقاء دقيقا لما يصل غلينا من معلومات مكونة لذخيرة المعرفة. صعوبة الابحار المعرفي أحيانا للوقوف علن مصادر المعرفة واستخلاصها من الكم الهائل للمعلومات المتوفرة، وذلك قبل توظيف المعرفة أو توليد معرفة جديدة منها. الالتزام المقيت للتخصص وإهمال العلوم البينية التي يمكن أن ترتبط بالتخصص، مما يشكل عائقا نحو فهم الظواهر المعرفية المترابطة. التعظيم من شأن الوسائط المتعددة غير القادرة علن نقل المعرفة الدفينة المعبرة عن الأفكار المجردة بأنساقها الرمزية. قبول التشظي المعرفي بمساراته ومسالكه التي قد تكون غير متناهية، مما يضعف تكامل المعرفة وشمو ها وعمقها وأساليب التحقق منها. وبإنزال تلك التحديات على واقعنا العربي نجد أن هنـاك تحـديات كبـيرة وكثيرة ومتنوعـة تقترب أو تبتعد بشكل ما مع سبق من تحديات - تقف أمام تكسوين رأس مـال عـربي وتشـكل موقفـا متناقضا لأنواع التفكير الأساسية والتي بدونها يتعذر تنمية التفكير الأداتي. نـدلل عسلى ذلك مـن رأي (علي، نبيل، 2009، 21-22) . بخصوص التفكير العربي في أنه: فكر أحادي الأبعاد يرئ الأمور عادة من زوايا واحدة، وهو ما يتعارض مع مفهوم التفكير المتوازي.

$$
\text { فكر يسو ده طابع رد الفعل، وهو ما يتنافن مع التفكير الاستشر افي. }
$$

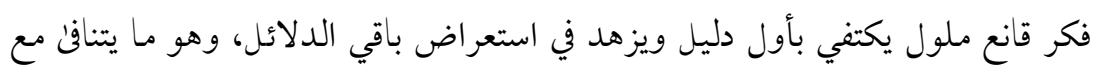

$$
\text { التفكير التبادلي. }
$$

فكر يميل علن اليقين وينشد الاجماع والتعامل مع القاطع، وهو ما يتنافن مع التفكير الاحتمالي.

\section{http://dx.doi.org/10.29009/ijres.3.1.2}


فكر وهنت صلاته مع العلوم الصورية من منطق ورياضيات ونظريات الأشكال والنظم،

$$
\text { ... وهو ما يتناقض مع التفكير التجريدي. }
$$

فكر ما أسهل أن ينزلق في متاهة التفاصيل التي تلهيه عن رؤية الصورة الشاملة، وهو مـا

$$
\text { يتنافن مع الفكر المنظومي. }
$$

فكر يعاني نرجسية القبيلة وهو ما يجعله عاجزا عن فهم الآخر المختلف، فتمركز حول ذاته،

$$
\text { وقد ضمرت لديه مهارات السجال والحوار، وهو ما يتنافن مع الفكر التواصلي. }
$$

فكر توفيقي، ينطلق من المبدأ القائل بأن الحقيقة وسط طرفين، وهو ما يتنافئ مع الفكر التركيبي القائم أساسا علن الدمج بين العناصر وتفعيل علاقات الجدل بينها (علي، نبيل،

يؤكد نبيل علي (171:2009) أن "ججتمع المعرفة هو من أجل الجميـع، ومسن صـنع الجميـع، وهو مجتمع التفرد لا الانفر اد، وألفة الصفوة مع العامة أو التجمـع مــع التـــع، والوفـاق مـع قبـول الاختلاف". . استراتيجيات تنميته قبل الولوج إلى كيفية تنميـة رأس المـال الفكـري، يلـزم التعـرض لمعايير - يراها الباحث - ضرورة له وهي: (1) وضوح الغاية مـن هـذا الرأسـال، (2) تـو افر الدقـة والعمق المعرفيين (3) إمكانية ربطه بأشكال أخـرى في سـياقات متباينـة، (4) شـامل لـرؤئ متباينـة ووجهات نظر متعددة، (5) متسق داخليا - أسباب وتبعات، مقدمات ونتائج، استتقر اء واستنباط مع معقولية الأفكار المطروحة وقابليتها لاختبار صدقها من زيفها، مع منطقية العـرض، (6) إمكانيـة

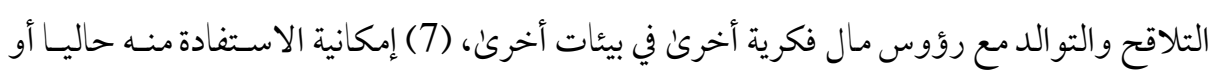

مستقبلا.

التنمية المستدامة لر أس المال الفكري

ويرئ الباحث أن رأس المال الفكري لا يمكـن تنميتـهـ أو استـدامة تجــده إلا بمقدرتهـ عـلن الابداع والخلقق، والايهان بالعقل المنطقي، والوجدان المهذب، والاستناد علنى الارادة الواعيـة - دون 
الاعتقاد دوما في الأنا المهزوم والآخر الضاغط. و عليه، يمكن تفعيل ذلك مـن خـلال اسـتراتيجيات أربع: التفكير خارج مألوف التفكير، والتفاعل الفكري، والتهجين الفكري، والاستهداء الفكري. التفكير خارج مألوف التفكير Think the unthinkable ويقصد به حث العقل على التفكير التباعدي والخروج عن النمطية في التفاؤل في الحلول لمشكلات متشابكة متداخلة، والولوج إلى مواقف وقضاي خلافية لبحث اسبابها العميقة غير المتداولة أو المطروحة، وإعادة رؤية المشكلات والتحديات والتطلعات من منظور مختلف، مع وضع البدائل والحلول غير المتوقعة بشكل يصعب - ولكن لا يستحيل - التنبؤ به مع إطلاق التداعي الحر للأفكار دون قيد أو شرط.

التفاعل الفكري Intellectual Interaction ويرتكز علن أنه لا حل و احد لكل مشكلة، ولا وجهة نظر مستقلة، ولا حوار بلا قضية. فالمشكلات لها أسباب غختلفة ونواتج متباينة وبدائل الحلول لا متناهية، والابداع في ذلك لا حد له، وبالتالي فإن الفكر يقدح الفكر

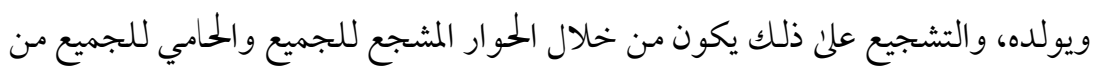

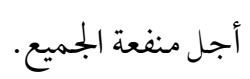
التهجين الفكري Intellectual Hybridization ويراه الباحث تداخل واندماج الأفكار الأصيلة أو الدفينة مع أفكار أخر لتنتج عنها أفكار مبتكرة حتى وإن بدا الأبوان متناقضان. فالأصل في رأس المال الفكري تجدده بدماء جديدة من خبرات وأفكار وممارسات سابقة،

$$
\text { ورؤئ واستشر افات وخواطر جديدة. }
$$

الاستهداء الفكري Seeking Intellectual Guidance وهو يدل علن اتخاذ الأفكار السابقة سبيلا لأفكار جديدة تحتاج إلى إعادة قراءة أو فحص أو تنظيم أو معالجة بأسلوب غير مألوف، مع الحفاظ علن مسيرة القديم والحديث من الأفكار وإشكالياتها وسبل التعامل

$$
\text { مer }
$$

رابعا: اقتصاد المعرفة

http://dx.doi.org/10.29009/ijres.3.1.2 
من المعلوم أن كل معرفة هي إفراز مـن المجتمـع، تـذيب الانقسـامـات بـين المعرفـة المتأصـلة و المعرفة العلمية وبين الخبرة العامة من الوجهات النظر الجزئية والممارسات المتفرقة بين خختلف أطراف المجتمع . ومع ذلك، فكافة المعارف ليست مشتركة بالتساوي، وهي ليست بجموعة من الأفكار سابقة

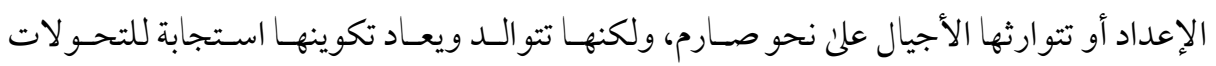
الاجتماعية والاقتصادية والسياسية والثقافية والمعلوماتية وغيرها وعندما تشير المبادرة الأساسية لنقد الاقتصاد السياسي (نقلا عن يورجن هابرمساس:2002) إلى أن "تطور رأس المال الثابت إلى أية درجة أصبحت فيها المعرفة الاجتماعية العامة قوة إنتاج مباشرة،

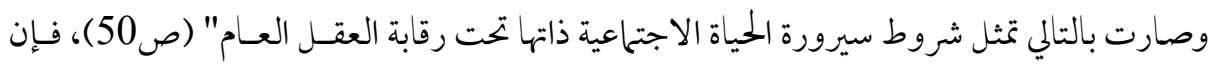

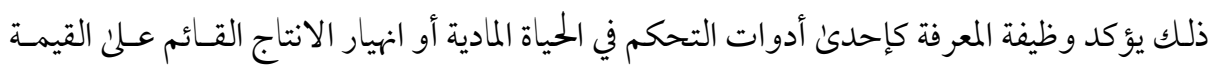
المادية التبادلية حتى وإن كان رأس المال المادي هو عصب الحياة في كل قوئ العلم و الطبيعة. وإنـا إذا كان ذلك رأس المال محصنا بالمعرفة الأداتية التي أوجدتها ظروف اجتماعية وسياسية وثقافية معينة، مع أنها قوة إنتاج غير مباشرة وغير ثابتة وتكاد تكون نسبية - لأمكنه أن يكون شكلا من أشكال السيطرة

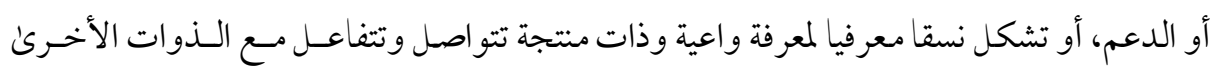

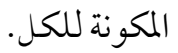
ونظر الديناميكية المعرفة وتعدد عملياتها، قدمت مدرسة كرينفيلد لمركز إدارة الأداء التجاري Cranefield School of Management's Centre for Business Performance Knowledge Process 2016،Starvic \& Marr Wheel و وهي ذات سبعة محاور:

توليد المعرفة Knowledge Generation وتشمل بجموعة من العمليات التي يتم تنفيذها لزيادة حجم أصول المعرفة، وهي ذات عمليتين رئيسيتين: اكتساب المعرفة من بيئة خارجية وخلق معرفة جديدة ابتداء في البيئة الداخلية. 
وضع خرائط للمعرفة Knowledge Mapping وهي عملية التعرف علن أصول المعرفة knowledge assets تشارك المعرفة Knowledge Sharing وهي العملية التي تسمح بنشر وإذاعة المعرفة توفيرا لتكرار المجهود و المعلومات المستخدمة في عمليات اتخاذ القرار، ولكن عملية النشر ذاتها قد تكون تحديا أمسام منتج المعرفة لأنها تمثل له مصدرا فريدا من مصادر القوة، وبالتالي قد يصعب الاستغناء عن هذا المصدر. نقل المعرفة Knowledge Transferringوهي عملية تمرير المعرفة بين النظم المعرفية للأفراد والمجموعات المختلفة من خلال قنوات معدة لهذا الغرض. تكويد/ترميز المعرفة Knowledge Codificationوهي عملية تهدف إلى إخضاع المعرفة وتشكيلها بأكواد مناسبة تشمل الكلمات والصور والأفلام، وتضم اقتناص المعرفة knowledge لإنجاز هدف معين، وتجسيد المعرفة knowleduring externalization مباشرة، ثم تمثيل المعرفة من خلال مجموعة من الأكواد أو الرموز المعلوماتية. تخزين المعرفة Knowledge Storing وهي عملية حفظ المعرفة لكي تكون متاحة في أي وقت من خلال قو اعد بيانات أو أدلة ارشادية Directories. تطبيق المعرفة Knowledge Application ويقصد بها تفعيل واستخدام وممارسة المعرفة

$$
\text { لكي تصبح مصدرا من مصادر القيمة المضافة. }
$$

وفي ضوء ذلك، يستعرض الباحث بعض التعريفات لاقتصاد المعرفة - منها ما هـو في ضـوء مكوناته أو خصائصه أو عملياته أو وظيفته أو منشئه أو ضرورته لتحسين جودة الحياة. يعسرف مـاهر المحروق (2009) الاقتصاد المعرفي بأنه دمسج للتكنولو جيا الحميثة في عنـاصر الإنتساج لتسهيل إنتـاج

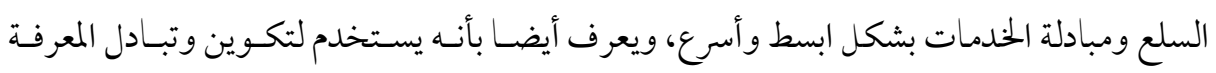
كنشاط اقتصادي "المعرفة كسلعة." أي تحويل المعلومات و المعارف العلمية آلي الشـكل الرقمي وهـو 
ذلك الاقتصاد الذي يحقق منفعـة مـن توظيـف المعرفـة واستغلال معطياتهـا في تقـديم مُنتجــات أو خدمات متميزة، جديدة أو مُتجددة، يُمكن تسويقها وتحقيق الأرباح منها وتوليـد الثـروة مـن خـلال

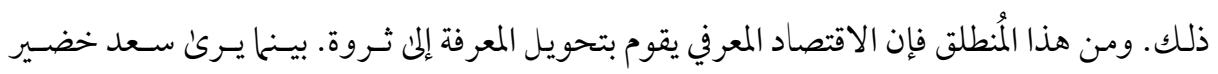
عباس الرهيمي (2011) الاقتصاد المعرفي هو ذلك الفرع من علم الاقتصاد الذي يهتم بعوامل تحقيق

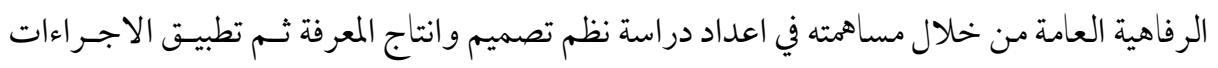

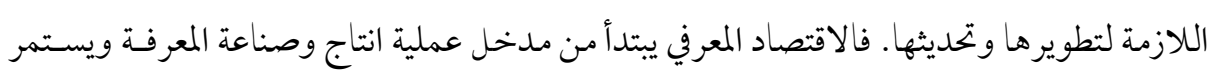

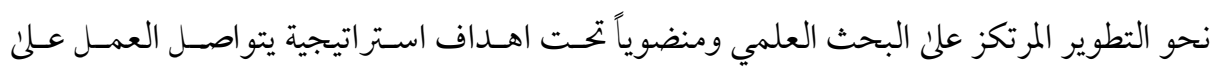

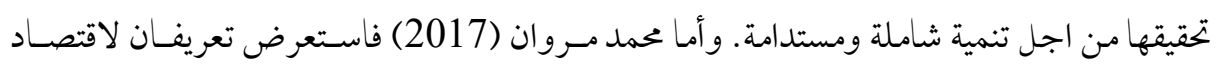

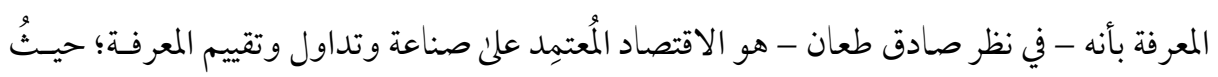
تقلّ فيه الأهيّة المترتبة علن تكاليف العمالة، كما لا يستخدم المفاهيم التقليديّة للاقتصاد، مثل النُدرة في

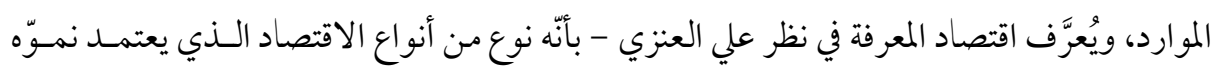
على نوعيّة وكميّة المعلومات المتاحة، والقدرة علن الوصول إليها. ويعرفه حداد Hadad (2017) بأنسه

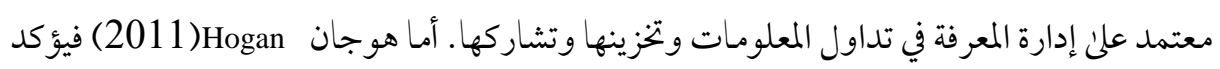

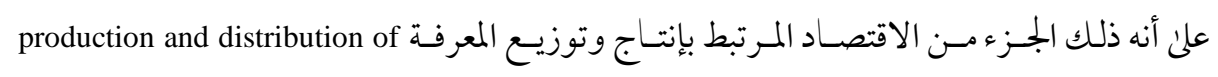

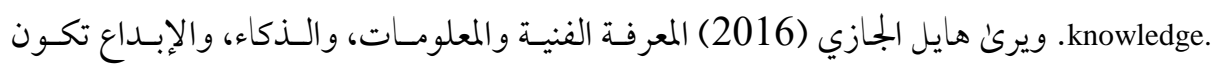
اقتصاد المعرفة. - ماد

ويعد بجتمع اقتصاد المعرفة الذي نعيشه اليوم، نتيجة التحول من بجتمع ذي اقتصـادصسناعي

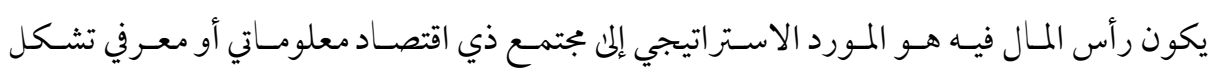
المعلومات فيه المورد الأساسي والاستراتيجي، حيث يركن بعض المحللـين الاقتصـاديين أن الحضـارة الحالية تحولت من اقتصاد صناعي إلى اقتصاد معلوماتي (مصطفي عبد العظيم: 2017)، وهذا مـا أكد عليه سباسي Spacey (2018) في أن اقتصاد المعرفة هو خلق وإيجاد قيمة عن طريق الـذكاء البشر-ي، لكنه يتطلب معرفة عريضة واسعة لامتلاك و استخدام ونقل المعرفة. 


\section{خصائص اقتصاد المعرفة}

تباينت خصائص اقتصاد المعرفة بين العلماء و الباحثين والخبراء. فمنهم من تناول سماته ومنهم

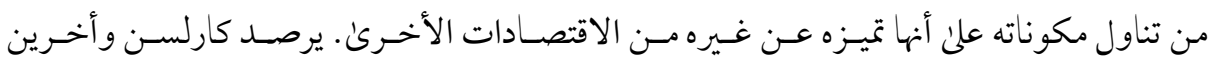
Karlsson et al. استثلمارات المعرفة مثل التعليم وإنتاج المعرفة، و (2) توسيع نطاق تطبيـق المعرفـة في تطـوير البضـائع والخدمات وإنتاجها وتوزيعهـا واستخدامها، بيـنما وايـت و أخـرون .White et al (2012) يـرون أن السمات الأساسية لاقتصاد المعرفة هي التجديد المفتوحOpen Innovation والتعليم Education وإدارة المعرفة مnowledge management والابداع Creativity ، ويكون لهذه السمات أسـاس تسـتند عليـه ألا وهو البنية التحتية لتكنولوجيا المعلومـات والاتصـالات، في حـين أن تابسكوت Tapscott (2014) حدد خصائص اقتصاد المعرفة في ثلاث: أن المعرفة هي العامل الأساسي للإنتاج، و اقتصاد المعرفة هو اقتصاد رقمي، و للافتراضية Virtualization دور مهم في اقتصاد المعرفة. يؤكد أنجر Unger(تحت الطبع) أن ما يميز اقتصاد المعرفة هو البنيـة العميقـة لـه والمتمثلـة في

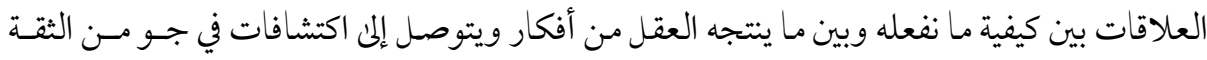
والوضوح و التعاون و الادارة الحكيمة للصراع وللمعرفة دوافع حددها أحمد الشاعر (2001): دوافع ذاتية يمثلها الدافع الفطري والــدافع النفسي والدافع الروحي والدافع العقلي، ودوافع خارجية تتمثل في الــافع الكــني والقـر آن الكـريم و الدافع الثقافي. و كلها تدعو الانسان لمعرفة نفسه وعدم الانحر اف بفطرته و النظر في مفردات الكـون

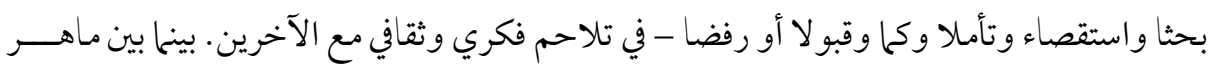

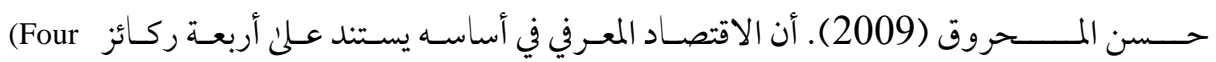
pillars) والاتصالات و الحاكمية الرشيدة، ما يميزه عن غيره من الاقتصادات الأخرىن. 
ويذكر هوجان Hogan (2011) أن للمعرفة خصائص تجعل لهـا تطبيقـات مهمـة للغايـة في

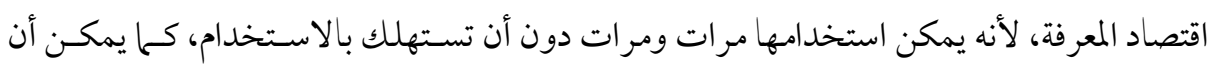

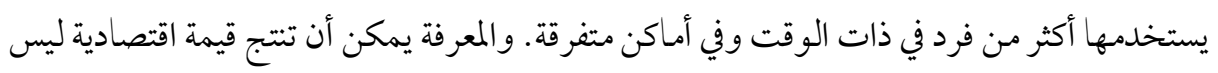

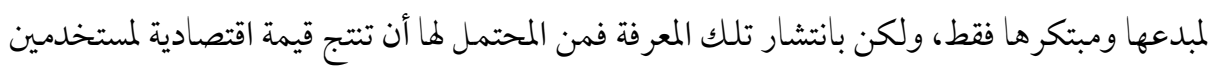

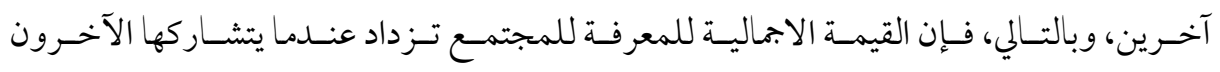
ويستخدمونها.

ولاقتصاد المعرفة خصائص يتميّز بها كما ذكر محمد مـروان (2017)، وهـي أن المعرفة تُثــل

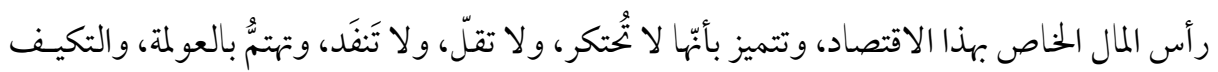

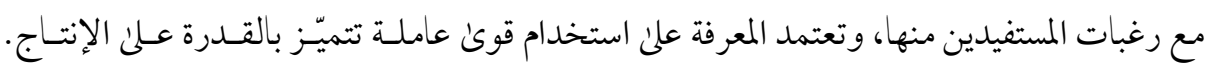

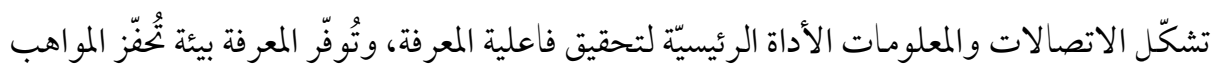
والإبداع.

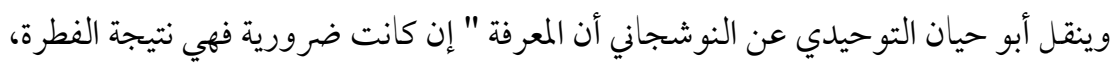

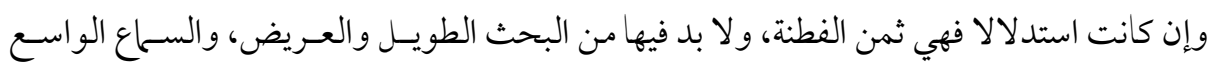

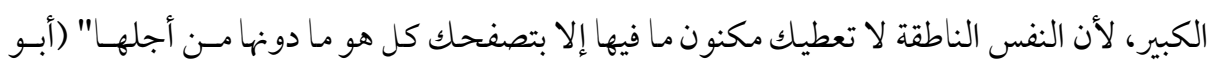
حيان التوحيدي، 1992: 364).

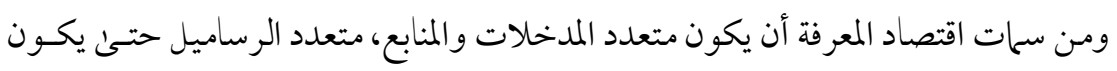

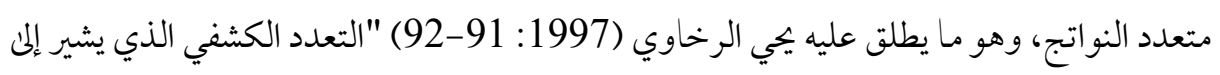

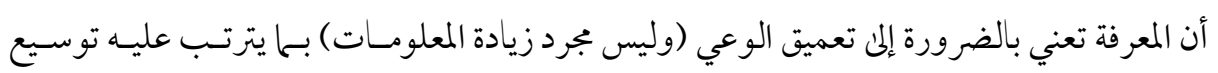
مساحة الرؤية". أهمية اقتصاد المعرفة يذكر محمد مروان (2017) أهمّ النقاط التي تشكّل أهمية اقتصاد المعرفة ومنها: تُعتبتر الأساس المستخدم للإنتاج وزيادة الثروة. 
تساهم المعرفة في زيادة الإنتاجيّة، وتحسين الأداء، وتقليل تكاليف الإنتاج، والحرص علن

$$
\text { تطوير نوعيته؛ }
$$

تساعد المعرفة علن دعم الدخل القوميّ؛ من خلال إنشاء المشاريع ومتابعة عو ائدها الماليّة، جنبا إلى جنب مع المساهمة بتوليد الدخل الفرديّ، والمرتبط بنشاطات المعرفة المباشرة أو غير

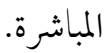
تساهم المعرفة بتوفير فرص عمل؛ وتحديداً ضمن المجالات المهنيّة التي تستخدم تقنيات تكنولوجيّة متقدمة ضمن اقتصاد المعرفة، كما تتميّز فرص العمل المتاحة بأنّا متنوعة،

$$
\text { ومتزايدة، وواسعة. }
$$

تشارك المعرفة بتحديث النشاطات الاقتصاديّة وتطويرها؛ مبّا يدعم نموّها بدرجة كبيرة، ويؤدي ذلك إلى استمراريّة تطور الاقتصاد بشكل سريع.

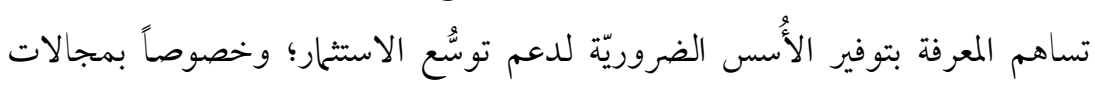
المعرفة العمليّة والعلميّة؛ ممّّ يؤدي إلى بناء رأس مال معرفي لتوليد إنتاج المعرفة.

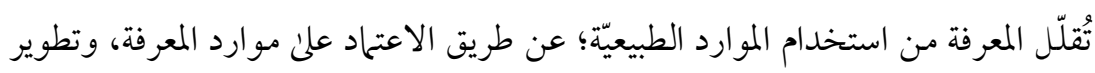
الموجودمنها. تساهم المعرفة بتغيير هيكلّة الاقتصاد؛ إذ تؤدي إلى زيادة الاهتحام بالإنتاج المعرفيّ المباشر وغير المباشر، وتعزّز الاستثمار برأس مال المعرفة، وتدعم الصادرات الخاصة بالمنتجات

المعرفيّة.

واقتصاد المعرفة - في نظر الباحث - مرتبط بالمنفعة أو المصـلحة. وهـي عسلن بعـدين: إمـا أن المعرفة مصلحة في إعمال العقل والتأمل و التدبر وضرب الفكـر بــالفكر وتحريـر العقـل مــن النمطيـة والثبات والجمود، وشحذه في تفعيل الحو اس و التعامل مع الو اقع بشـل منهجي، أو دعـا لأفعـال أداتية وتكوين إدراكات وتصورات وفروض جديدة، مع تأكيد كينونته ومرونته وحريته واستقلاليته، ويمكن أن يطلق علن هذا البعد المصلحة النظرية للمعرفة. وأما إذا كانت "المصلحة هي الرضا الـذي وصري 
يربطنا مع تصور وجود موضوع ما أو وجود فعل ما، وهي تهدف إلى الكينونة، لأنها تعبر عـن علاقـة

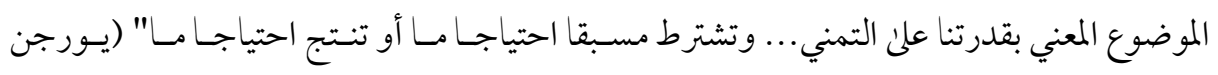
هابرماس، 2002:186)، أي يتقاسمها من أنتجها ومن احتاج إليها، من أنتجها ومن اكتفي بنقلها، من وضع منهجيتها وشروطها وعملياتها وبين من طبقها عمليا. وبين إنتاجها و استهلاكها مصلحة للجميع في توليد معارف جديدة. فالمصلحة توجه المعرفة وتتعلق بالأفعال التي ترسخ شروطـا معينـة ممكنة، ولو كان ذلك بتشكيل مختلف، وهذا البعد يمكن أن يطلق عليه المصلحة العملية للمعرفة. وأرجع سعد خضـير عبـاس الرهيمي (2011) أسـباب الـنقص في انتـاج عنـاصر المعرفـة ونشرها في الدول العربية المن انخفاض مستوى التعليم، و انخفاض مستوى البحث و التطـوير، وغلبـة الطابع البيروقراطي وضعف التخصيصات المالية، ووجود بعض التوجهات المغلوطة لتطوير المعرفة، ولكن اقترح في نهاية بحثه استراتيجية عربية لإنجاز الاقتصاد المعرفي من سلها التخطيط لاستراتيجية وطنية تقوم على انتاج المعرفة، وتطوير بنية تحتية ترتكـز المى تكنولوجيـا المعلومـات والاتصـالات مـع التأكيد علن النظر إلى اقسام المعلومات الآتية: Information content: صناعة محتوى المعلومات Information Delivery صناعة تسليم (بث المعلومات) صناعة معالجة المعلومات Information Processing. ولاقتصاد المعرفة مجموعة من المتطلبات الرئيسيّة من أجل ضمان استمراريّته وتطـوره: تـوفير بنية اتصالات وتكنولوجيا معلومات من أجــل المســاهمة في بنـاء مجتمـع معلومـاتيّ. تطـوير القـوانين المستخدمة لتتناسب مع اقتصاد المعرفة. تأسيس وتطوير رأس المال البشريّ؛ من خلال تـوفير الـدول للمناخ المُساعد للمعرفة حتى تصبح أهمّ عنصر إنتاجيّ. إدر اك المنشآت المتنوعة والمستشمرين لأهمّيّة

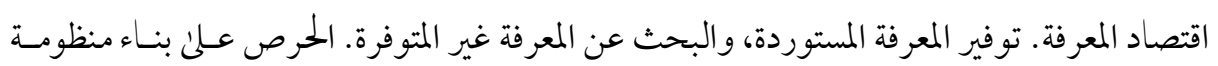

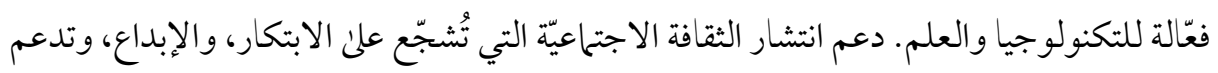

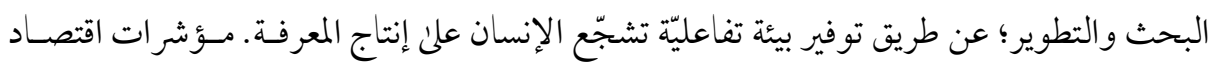


المعرفة توجَد بجموعة من المؤشرات المرتبطـة باقتصـاد المعرفـة، وتُسـتخدم للدلالــة عـلن أنسّه الـنمط

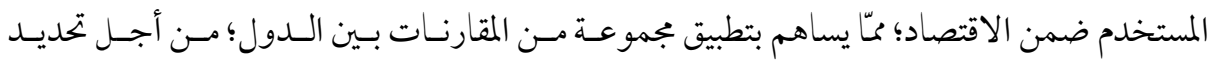
مستوى تطوّرها الاقتصاديّ. العلاقة برأس الملال الفكري

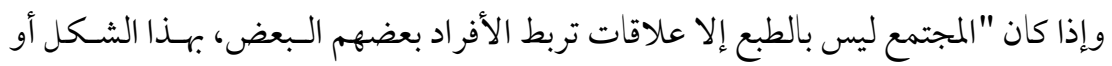
ذاك، كما أن العلاقات هي تفاعلات مترابطة متحركة، لا قو الب ثابتة، وتتضمن التفـاعلات الضـمنية المترابطة، التي تؤلف مجتمعا بشريا، تبادل الأخذ و العطاء في المشاركة وفي الاسهام الذي يضاعف مـن قدرة العوامل المتفاعلة، ويعمقها ويوسع من أهميتها" - كما أكد جون ديوي (2001: 74) - فإن من باب أولى أن يكون بجتمع المعرفة بجتمعا تعاونيا تشاركيا يهدف إلى التنـوير المتبـادل والتصـفح العقلي و النقاء الوجداني، مع تحكيم عقل وتمحيص نقل، والاحتجاج بالصحيح والصريح. فكل فرد في هـذا المجتمع أو ذاك يؤدي بعض ما يدرك من معرفة، كما لا يستأثرن بحكمة معرفية ير اها منقوصة أو غائبة عن الآخرين، فكل معرفة فوق معرفة بالموضوع، ومعرفة دون معرفة بالفائدة، لا المعرفة ليست بالظنة أو التوهم، أو الاغماض عن مسألة أو قضية والإبحار في أخرىن، وإنها بر أي من تلقيح الظـن والتـوهم بشر اكة العقل والتجربة، فالكل لديه هذا وذاك ولكن بقدر متفاوت.

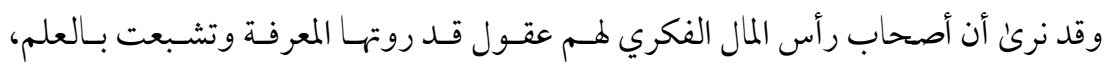
ساعدهم ذلك على ممارسة ملكاتهم العقلية - إما إشباعا لفضولهم، أو تحقيقا للذة عقليـة، أو لمصـلحة أو لمنفعة في مجال المال أو الأعمال أو كليهما، أو للحصول علن الأمـان أيا كان مصــره ومبعثـه ونوعـه. وهذا يعني أنهم وغيرهم مدفوعون من أجل المصالح الذاتيـة الفرديـة أو الجمعيـة كأصسحاب لــرأس المال، خاصة وأن رأس المال الفكري ليس من قبيـل الاقتصـاد الثابـت stationary economy و الملكيـة المطلقة، وإنها من الاقتصاد المتوسع بغير حدود ينطوي علن تحويل كل فكرة - مهما كانت غريبة وغـير مألوفة - إلى أداة تستخدم لتوليد فر ائد الأفكار، ولا يعنـي ذلـك ألا تكــــ هنـاك استقلالية فكريـة

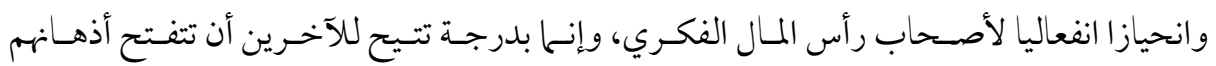


للتخلص من جاهزية الأفكار وجاهزية الرؤئ، وعبثية التطلعات، وتفاهة التوقعات، والاعتماد الكلي على ما تم إنتاجه. ولأن هناك منافسة شديدة يتسم بها سـوق اقتصـاد المعرفـة، وقصرـمتز ايـــلعمـر منتجـات

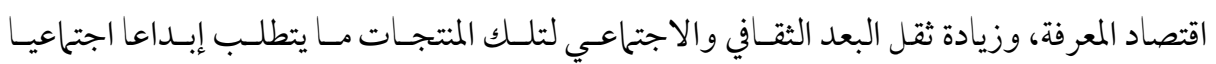

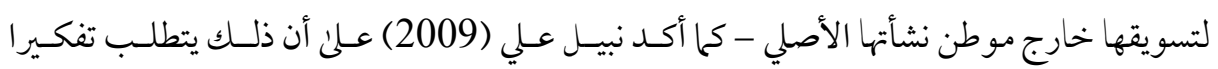
إبداعيا خلاقا يستفيد من رأس الملال النقدي أو البشري في تكوين رأس مـال فكري يقلل الفجـوة بـين

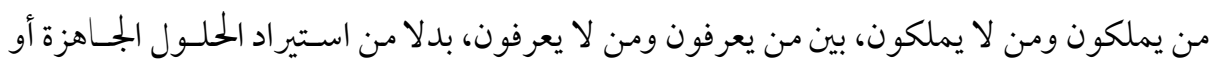

$$
\text { الاستجداء المعرفي من الآخرين. }
$$

\section{خامسا: رؤية مستقبلية نحو منهج متمايز يجقق أهداف الألفية الثالثة}

نظر التزايد دور التكنولوجيا وتوظيفها في بيئة التعلم، أصبح من اللازم والضروري أن تتغير

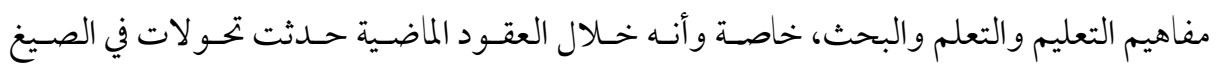
والنهاذج الفكرية وثمر اتها: من تعليم عادة الانتاج إلى تعليم منتج، ومن السـلوكية إلى البنيوية، ومن التركيز علن المعلم إلى التركيز على المتعلم، ومن التدريس إلى تسهيل التعلم، ومن مدخل التربية القائم على المحتوئ إلى ذلك القائم علن المخرجات، ومن التقييم القائم على المحتوى إلى التقييم

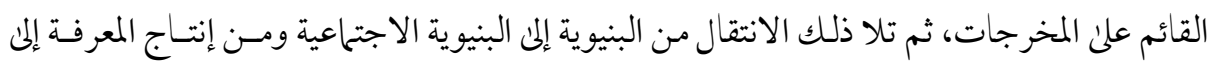
تشكيل المعرفة، ثم ظهر حديثامـا يطلق عليه الابحارية (2005) Navigationism Brown، وهي شكل

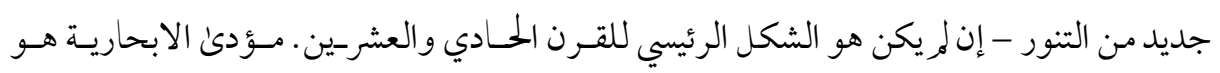

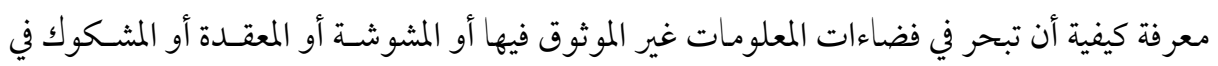
صحتها وصدقها ومو ضو عيتها، أو معرفة معلومات تحس معها بالر احة عنـدما تكتشـف شيئا معينـا بحدود معينة، ويكون المعلم هو مصدر كيف تفعل ذلك الابحـار لأنـه يملـك المهـارات و الكفايـات المتطلبة للابحار، ويصبح بناء المعرفة أمرا جانبيا. أما المسألة الأساسية هي أن تكون قادراعلئ الابحار 
والولوج داخل الانفجار المعرفي الهائل، ويكون محور التعليم هو الابحار في محيط المعرفـة المتاحـة مـن

$$
\text { أجل حل مشكلات حياتية حقيقية أو متوقعة. }
$$

وعليه، يرئ الباحث أنه علن المـنهج المتهايـز أن يراعي تلـك التحــولات في الصسيخ والأدوار

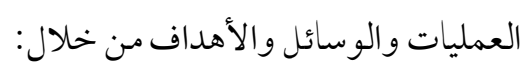

$$
\text { شمول المنهج علن عناصر الو اقع الافتراضي والو اقع المعزز. }
$$

تحقيق أهداف المنهج ووظائفه في استثمار المعرفة knowledge investment|نتاجا

$$
\text { واستهلاكا وتشاركا وإدارة. }
$$

تحقيق الانسجام بين طرق المعرفة المختلفة ways of knowledge في مساراتها ووظائفها

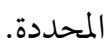

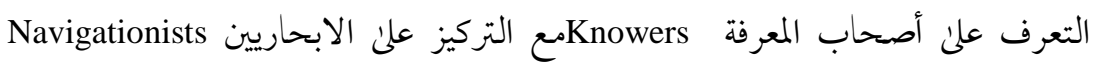

$$
\text { لإنشاء رأس مال فكري متجدد يقوم على أصول موضوعية موثوق في صحتها وأهيتها. }
$$

Cognitive conflict التركيز علن التلاقح والتوالد المعرفي بديلا عن الصراع المعرفي والتنازع الفكري، فالمعرفة تولد المعرفة لأنها ضرورة وجود، مع التواصل المعرفي الجامع للعلوم لمعالجة قضايا الانسان وتحقيق الرفاه.

التخفيف من الاجهاد الفكري المنفرد، مع التركيز علن التفاكر

.Ideation

تفعيل الاقتداء المعرفي مع الاتجاه نحو التمكين المعرفي knowledge empowerment، فلأمة الأكثر معرفة هي أرسخ وأشد قوة. 


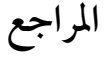

1. أبو الشامات، محمد أنس (2012). اتجاهات اقتصاد المعرفة في البلدان العربية، مجلة جامعة

دمشق للعلوم الاقتصادية والقانونية، المجلد، 28العدد الأول، صص 591-610.

2. التوحيدي، أبو حيان (1992). المقابسات، تحقيق حسن السندوبي، ط2، دار سعاد الصباح،

الكويت.

3ttps://mawdoo3.com: الجازي، هايل. (2016). مفهوم اقتصاد المعرفة، متاح على الموقع 4. الحمدان، حسام عيسى. (2009). المنهجية المثلى لتوظيف اقتصاد المعرفة في تحقيق النهضة

$$
\text { التنموية في سورية، كلية الاقتصاد، جامعة دمشق، سورية. }
$$

5. خلف، فليح حسن. (2007). اقتصاد المعرفة، جدار اللكتاب العالمي، عمان، الأردن.

6. خليفة، منى محي الدين. (2012). نحو منظومة تعليمية تساهم في تنمية ونهضة المجتمع (صص 683-700). المؤتمر العلمي السنوي (العربي السابع الدولي الرابع) بعنوان: إدارة المعرفة وإدارة رأس الملال الفكري في مؤسسات التعليم العالي في مصر والوطن العربي، كلية التربية النوعية بالمنصورة وفرعيها بميت غمر ومنية النصر، جامعة المنصورة، مصر 7. ديوي، جون. (2001). الفردية قديا وحديثا، ترجمة خيري حماد، مكتبة الأسرة: أمهات الكتب، الهيئة العام للكتاب، القاهرة.

8. الرخاوي، يجي. (1997). مر اجعات في لغات المعرفة، سلسلة اقرأ، العدد 620، دار المعارف، القاهرة.

9. الرهيمي، سعد خضير. (2011). الاقتصاد المعرفي أساس التنمية الاقتصادية الاجتحاعية في الدول العربية، كلية القانون - جامعة بابل. 10.زايد، أحمد (2006). سيكولوجية العلاقات بين الجلماعات: قضايا في الهوية الاجتماعية وتصنيف الذات، سلسلة عالم المعرفة، العدد 326، المجلس الوطني للثقافة والفنون

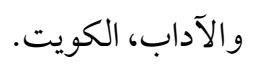


11.الزهيري، إبراهيم عباس. (2012). رأس المال الفكري: الخيار الاستراتيجي المستقبلي لمؤسسات التعليم العالي (صص17-45) المؤتمر العلمي السنوي (العربي السابع الدولي الرابع) بعنو ان: إدارة المعرفة وإدارة رأس المال الفكري في مؤسسات التعليم العالي في مصر

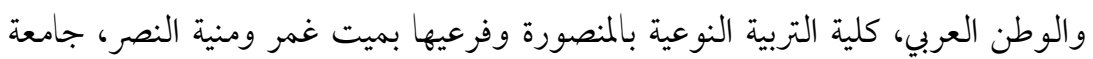
المنصورة، مصر.

12. السامرائي، نعحان عبد الرازق. (2001). نحن والحضارة والشهود، سلسلة كتاب الأمة، العدد 81، وزارة الأوقاف و الشئون الاسلامية، قطر.

13. سليان، جمال داود. (2009). اقتصاد المعرفة، دار اليازوري للنشر والتوزيع، عحان، الأردن. 14.سوردار، نانديني. (2002). هل يمكن أن يؤدي "تأصيل الطابع الفطري، والوطني، والروحي"... إلى وضع خطة للتعليم: المعرفة المتأصلة، المجلة الدولية للعلوم الاجتماعية،

$$
\text { العدد173، اليونسكو، القاهرة، صص 131-137. }
$$

15.السورطي، يزيد عيسى.(2009). السلطوية في التربية العربية، سلسلة عالم المعرفة، العدد

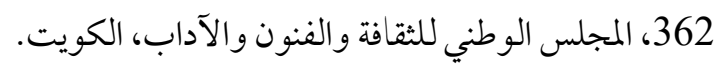

16.الشاعر، أحمد عبد الحميد (2011). المعرفة في التصور الانساني: مصادرها وخصائصها، سلسلة دراسات إسلامية، العدد 191، المجلس الأعلن للشئون الاسلامية، وزارة الأوقاف، مصر.

17.شنودة، إميل فهمي (2012). بعض النهاذج العالمية لقياس واقع رأس المال الفكري وإدارة المعرفة (صص11-16). المؤتمر العلمي السنوي (العربي السابع الدولي الرابع) بعنوان: إدارة المعرفة وإدارة رأس المال الفكري في مؤسسات التعليم العلاي في مصر والوطن العربي، كلية التربية النوعية بالمنصورة وفرعيها بميت غمر ومنية النصر، جامعة المنصورة، مصر. 18. عبد العظيم، مصطفي. (2017). اقتصاد المعرفة.. التحول الثالث في تاريخ تطور المجتمعات

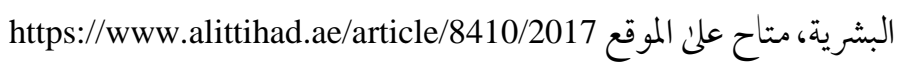


19.علي، نبيل. (2009). العقل العربي ومجتمع المعرفة، سلسلة عاله المعرفة، العدد 370، جزء2،

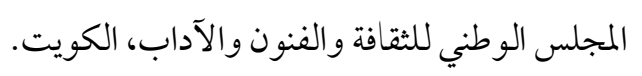

20. عليان، ربحي مصطفي. (2010). اقتصاد المعلومات، دار صفا للنشر والتوزيع، عمان،

$$
\text { الأردن. }
$$

21. لجنة شئون المجتمع العالمي (1995). جيران في عالمرواحد، ترجمة بجموعة من المترجمين، سلسلة عالر المعرفة، العدد 201، المجلس الوطني للثقافة والفنون والآداب، الكويت. 22.لي، تانيا موراي. (2002). التصفية العرقية، والمعرفة المتواترة، ومضلات الاستقرار الدائم، المجلة الدولية للعلوم الاجتماعية، العدد 173، اليونسكو، القاهرة، صص 113-130. 23. المحروق، ماهــر حسـسن. (2009). دور اقتصاد المعرفة في تعزيز القدرات التنافسية للمرأة

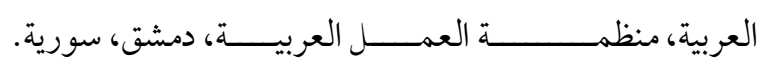

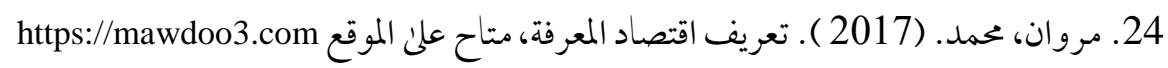
25.الهادي، طاهر محمد. (2017). تخطيط وتصميم التدريس، مذكرات جامعية، كلية التربية: جامعة قناة السويس، مصر. 26. الهادي، طاهر محمد. (2017). دراسات متقدمة في المناهج، مذكرات جامعية، كليـة التربية: جامعة قناة السويس، مصر. 27. الهادي، طاهر محمد. (2018). أدوات التخطيط الاستراتيجي، ورقــــــة عمــــلـ مقدمة لندوة بعنوان رؤية مشتركة لتطوير منظومة التعليم في مصر، لجنة التعليم بمجلس النواب بالاشتراك مع الجمعية التربوية للدراسات الاجتماعية ومركز الأهرام للدراسات الاستراتيجي، فندق كوبينيسكي بالقاهرة (الفترة 30-31 أغسطس 2018). 28.اهادي، طاهر محمد. (2011). أسس المناهج المعاصرة، دار المسيرة للنشر والتوزيع، عمان: الأردن. 
29.اهادي، طاهر محمد. (2016). تخطيط وتصميم المناهج، مذكرات جامعية، كلية التربية: جامعة قناة السويس، مصر.

30.الهادي، طاهر محمد. (2018). الإرجونوميكا الخضراء ومنهج الاستدامة: المفاهيم والتحديات والكفايات: ورقــة عمــــلـل مقدمة للمؤتمر الدولي الأول لقسم المناهج وطرق التدريس بكلية الدراسات العليا للتربية بجامعة القاهرة، مركز المؤتمرات لجامعة القاهرة (الفترة 5 - 6 ديسمبر 2018).

31. الهادي، طاهر محمد. (2018). وظائف المنهج ومجتمع المعرفة في الألفية الثالثة: رؤية مستقبلية، ورقة بحثية مقدمة للمؤتمر الدولي لأكاديمية طيبة بالقاهرة بعنوان الحوار المصري الروسي: تطوير التعليم العالي للتنمية المستدامة، مركز المؤتمرات لجامعة القاهرة (الفترة 20-21 أكتوبر 2018).

32.الهادي، طاهر محمد. وموسئ، محمود علي (2018). تقييم بيئة التعلم الافتراضية كمدخل

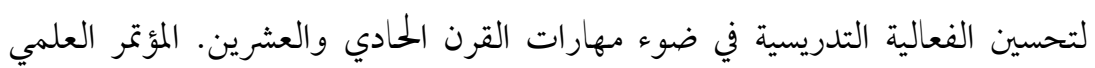
الخامس والدولي الثاني للجمعية العربية للقياس والتقويم بعنوان التقويم مدخل للجودة التعليم المنعقد بأكاديمية طيبة بالمعادي - القاهرة (4 أغسطس 2018). 33. هاو، ألن. (2015). النظرية النقدية، ترجمة ثائر ديب، مكتبة الأسرة، الهيئة المصرية العامة للكتاب، القاهرة. 34. هايرماس، يورجن. (2002). المعرفة والمصلحة، ترجمة حسن صقر . المشروع القومي للترجمة، العدد 326، المجلس الأعلى للثقافة، القاهرة.

35. الهيتي، عبد الستار. (2004). الحوار: الذات والآخر . سلسلة كتاب الأمة، العدد 99، وزارة الأوقاف والشؤون الاسلامية، قطر. 


\section{References:}

- Abdul Azim, Mustafa. (2017). Knowledge Economy: The Third Transformation in the History of the Development of Human Societies, available at https://www.alittihad.ae/article/8410/2017 (In Arabic).

- Abu Shamat, Mohammed Anas (2012). Knowledge Economy Trends in Arab Countries, Damascus University Journal for Economic and Legal Sciences, Vol. 28, No. 1, ff 591-610. (In Arabic).

- Al-Hadi, Taher Mohammed. (2011). Foundations of Contemporary Curricula, Al-Masirah Publishing \& Distribution, Amman: Jordan. (In Arabic).

- Al-Hadi, Taher Mohammed. (2016). Curriculum Planning and Design, University Notes, Faculty of Education: Suez Canal University, Egypt. (In Arabic).

- Al-Hadi, Taher Mohammed. (2017). Advanced Curriculum Studies, University Notes, Faculty of Education: Suez Canal University, Egypt. (In Arabic).

- Al-Hadi, Taher Mohammed. (2017). Teaching Planning and Design, University Notes, Faculty of Education: Suez Canal University, Egypt. (In Arabic).

- Al-Hadi, Taher Mohammed. (2018). Curriculum and Knowledge Society Functions in the Third Millennium: A Future Vision, Research Paper presented to the International Conference of the Thebes Academy in Cairo, The Egyptian-Russian Dialogue: Developing Higher Education for Sustainable Development, Cairo University Conference Center (20-21 October 2018). (In Arabic).

- Al-Hadi, Taher Mohammed. (2018). Green Ergonomics and Sustainability Approach: Concepts, Challenges and Competencies: Working paper presented to the First International Conference of the Department of Curriculum and Instruction, Faculty of Graduate Studies, Cairo University, Cairo University Conference Center (5-6 December 2018). (In Arabic).

- Al-Hadi, Taher Mohammed. (2018). Strategic Planning Tools, working paper presented to a symposium entitled: A common vision for the development of the education system in Egypt, the Education Committee of the House of 
Representatives in conjunction with the Educational Society for Social Studies and Al-Ahram Center for Strategic Studies, Kubinski Hotel in Cairo (30-31 August 2018). (In Arabic).

- $\quad$ Al-Hadi, Taher Mohammed. Mossa, Mahmoud Ali (2018). Evaluate the virtual learning environment as an input to improve teaching effectiveness in the light of 21 st century skills. The 5th and 2nd International Scientific Conference of the Arab Society for Measurement and Evaluation, entitled "Evaluation: An Introduction to the Quality of Education" held at Thebes Academy in Maadi - Cairo (August 4, 2018). (In Arabic).

- Al-Hiti, Abdul Sattar. (2004). Dialogue: self and the other. The Book of the Nation, No. 99, Ministry of Awqaf and Islamic Affairs, Qatar. (In Arabic).

- Ali, Nabil. (2009). The Arab Mind and the Knowledge Society, World of Knowledge Series, No. 370, Part 2, National Council for Culture, Arts and Letters, Kuwait. (In Arabic).

- $\quad$ AlMahrook, Maher Hassan. (2009). The Role of the Knowledge Economy in Enhancing the Competitiveness of Arab Women, Arab Labor Organization, Damascus, Syria. (In Arabic).

- Al-Rakhawi, Yahya (1997). Reviews of Knowledge Languages, Iqraa Series, Issue 620, Dar El Maaref, Cairo. (In Arabic).

- $\quad$ Alsorti, Yazid Issa. (2009). Authoritarianism in Arab Education, Knowledge World Series, No. 362, National Council for Culture, Arts and Letters, Kuwait. (In Arabic).

- Al-Tawhidi, Abu Hayyan (1992). Interview, Hassan Al-Sindoubi, 2nd floor, Dar Souad Al-Sabah, Kuwait. (In Arabic).

- Al-Zuhairi, Ibrahim Abbas. (2012). Intellectual Capital: The Future Strategic Option for Higher Education Institutions (pp. 17-45) Annual Scientific Conference (Seventh Arab International Fourth) titled: Knowledge Management and Intellectual Capital Management in Higher Education Institutions in Egypt and the Arab World, Faculty of Specific Education in 
Mansoura and its two branches in Mit Ghamr and Meniet El Nasr, Mansoura University, Egypt. (In Arabic).

- Bratianu, C. (2013). The triple helix of the organizational knowledge. Management Dynamics in the Knowledge Economy, 1(2), 207-220.

- Bratianu, C. (2015). Organizational knowledge dynamics: managing knowledge creation, acquisition, sharing, and transformation. Hershey: IGI Global.

- Bratianu, C., and Orzea, I. (2013). The entropic intellectual capital model. Knowledge Management Research \& Practice, 11(2), 133-141.

- Brown, T. (2006). Beyond constructivism: Navigation in the knowledge era. On the Horizon, 14(3), 108-120.

- $\quad$ Chen ,C. (2008). The shift to 21st century literacies: A cross-case study of EFL learning through online publishing projects. Ph.D. Dissertation. School of Education, Indiana University. UMI Number 3324510.

- Committee on World Community Affairs (1995). Jeeran in One World, Translation by a group of translators, Knowledge World Series, Issue 201, National Council for Culture, Arts and Letters, Kuwait. (In Arabic).

- Dewey, John. (2001). Individualism, Old and New, translated by Khairi Hammad, Family Library: Mothers of Books, General Book Authority, Cairo. (In Arabic).

- Educateiowa (2017). Strategies for differentiated instruction: New visions for public schools. Available at: http://www. educateiowa.gov/..0809_pk12_dl_strategiesForDifferentiatedInstruction.pd $\mathrm{f}$

- $\quad$ Fadel,C.; Bialik, M. and Trilling, B. (2015). Four-dimensional education: The competencies learners need to succeed. Center for Curriculum Redesign

- $\quad$ Farmer, D. (27 January 1996). adapted from text written for an educational video/booklet package,Meeting the Needs of Gifted Students in the Regular Classroom. 
- $\quad$ Fisher, D.(2014). Fostering 21st Century Skills in Engineering Undergraduates through Co-Curricular Involvement. 21st ASEE Annual Conference and Exposition. Indianapolis, IN Paper ID \#9561.

- Garrison, D. (2011). E-learning in the 21st century: A framework for research and practice. Routledge.

- $\quad$ Gibson-Cayouette, L. (2010). Knowledge and Understanding of 21st Century Skills through Educator Externships: Programs in Southern New England, Ph.D. dissertation. School of Education ,Johnson and Wales University. UMI Number: 3390635.

- Gregory, G. and Chapman, C. (2002). Differentiated instruction strategies: One size doesn't fit all. Thousand Oaks, CA: Crown Press.

- Guido, M. (2016). Differentiated Instruction Strategies and Examples. Available at: https://www.prodigygame.com/blog/differentiatedinstruction-strategies-examples-download/

- Hadad, S. (2017). Knowledge Economy: Characteristics and Dimensions. Management Dynamics in the Knowledge Economy, 5(2), 203-225; DOI

- Hallinan, M. and Kubitschek, W. (1999). Curriculum differentiation and high school achievement. Social Psychology of Education, 3(1-2): 41-62.

- Hamdan, Hossam Issa. (2009). The optimum methodology for employing knowledge economy in achieving developmental renaissance in Syria, Faculty of Economics, Damascus University, Syria. (In Arabic).

- Haw, Allen. (2015). Critical Theory, Translated by Thaer Deeb, Family Library, Egyptian Book Organization, Cairo. (In Arabic).

- $\quad$ HERMAS, Jürgen. (2002). Knowledge and interest, translated by Hassan Saqr. National Translation Project, No. 326, Supreme Council of Culture, Cairo. (In Arabic).

- $\quad$ Hertberg-Davis, H. (2009). Myth 7: Differentiation in the regular classroom is equivalent to gifted programs and is sufficient classroom teachers have the time, the skill, and the will to differentiate adequately. Gifted Child Quarterly, 53(4), 251-253.

\section{http://dx.doi.org/10.29009/ijres.3.1.2}


- Hogan, T. (2011). An overview of the knowledge economy with a focus on Arizona, A Report from the Productivity and Prosperity Project (P3), L. William Seidman Research Institute W. P. Carey School of Business Arizona State University. https://www.ortingschools.org/cms/lib/WA01919463/Centricity/domain/32 6/purpose/resources/Key\%20Principles\%20of\%20a\%20Differentiated $\% 20$ Classroom.pdf

- Jazzy, Hayle. (2016). The concept of knowledge economy, available at: https://mawdoo3.com. (In Arabic).

- Johnson, A. (Fall 2001). How to use thinking skills to differentiate curricula for gifted and highly creative students. Gifted Child Today, 24 (4). 58.

- $\quad$ Karlsson, C., Börje J., and R. Stough R., (2009). Human capital, talent and regional growth. CESIS Electronic Working Paper Series Paper No. 191, JIBS and CESIS, School of Public Policy.

- Khalaf, Falih Hassan. (2007). Knowledge Economy, Wall of the World Book, Amman, Jordan. (In Arabic).

- Khalifa, Mona Mohiuddin. (2012). Towards an educational system that contributes to the development and renaissance of society (ff 683-700). Annual Scientific Conference (Seventh International Arab) entitled: Knowledge Management and Intellectual Capital Management in Higher Education Institutions in Egypt and the Arab World, Faculty of Specific Education in Mansoura and its two branches in Mit Ghamr and Menia ElNasr, Mansoura University, Egypt. (In Arabic).

- Lee, Tanya Murray. (2002). Ethnic Liquidation, Frequent Knowledge, and Implications of Permanent Stability, International Journal of Social Sciences, No. 173, UNESCO, Cairo, pp. 113-130. (In Arabic).

- $\quad$ Leliaert, P.; Candries,W. and Tilmans, R. (2003). Identifying and managing IC: a new classification. Journal of Intellectual Capital, 4 (2), 202-214. 
- $\quad$ Lin, C. (2018). Intellectual capital of South Africa: a comparison with Poland and Romania. Journal of Intellectual Capital, 19 (3), 498-518, https://doi.org/10.1108/JIC-12-2016-0146

- $\quad$ Lin, C. and Edvinsson, L. (2011). National Intellectual Capital: A Comparison of 40 Countries, Springer Publishing Co, NY.

- $\quad$ Lin, C.; Edvinsson, L.; Chen, J. and Beding, T. (2014). National Intellectual Capital and the Financial Crisis in Israel, Jordan, South Africa, and Turkey, Springer Publishing Co, New York, NY.

- $\quad$ Marwan Mohammed. (2017). The definition of knowledge economy, available at https://mawdoo3.com (In Arabic).

McHenery, R. \& Giles, J. (2016). A differentiated curriculum: Same same ... but different? Available at: http://nepeantutoring.com.au/differentiatedcurriculum-samebut-different/

- $\quad$ Nonaka,I. and Trakevchi, N. (1995). The knowledge. Greating Company,NY: Oxford University Press.

- $\quad$ Olayan, Profit Mustafa. (2010). Information Economy, Safa Publishing House, Amman, Jordan. (In Arabic).

- $\quad$ Olomolaiye, A. \& Egbu, C. (2016). Tacit vs. explicit knowledge - the current approaches to knowledge management. Personal contact (e-mail: a.olomolaiye\&gaal.ac.uk).

- Ozanne, S. (2013).The 21st Century 8 C's. Available at: https://prezi.com/q61hozbzwzsa/the-21st-century-8-cs/

- $\quad$ Page,R. and Valli, L. (Eds.) (1990). Curriculum differentiation: Interpretative studies in US secondary schools. Suny Series, Frontiers in Education.

- Paoletti, P. (2018). Pedagogy for the third millennium Available at: fondazione@fondazionepatriziopaoletti.

- Perner, D. (2004). Changing teaching practices: using curriculum differentiation to respond to students' diversity. UNESCO Digital Library.

- Petty, G. (2004). Differentiation - What and how. Available at: http://www. googlew.co.uk/?gws rd=l\#q=differentiation+what+and+how+getoff+petty 
- $\quad$ Poet, Ahmed Abdul Hamid (2011). Knowledge in Human Perception: Sources and Characteristics, Islamic Studies Series, No. 191, Supreme Council for Islamic Affairs, Ministry of Awqaf, Egypt. (In Arabic).

- $\quad$ Rahimi, Saad Khudair. (2011). Knowledge economy is the basis of socioeconomic development in the Arab countries, Faculty of Law - University of Babylon. (In Arabic).

- Rennie, M. (1999). Accounting for knowledge assets: Do we needa new financial statement? International Journal of Technology Management, 18(6), 648-659.

- Samurai, Numan Abdul Razek. (2001). We, Civilization and Witnesses, The Book of the Nation, No. 81, Ministry of Awqaf and Islamic Affairs, Qatar. (In Arabic).

- Sardar, Nandini. (2002). Can "Rooting Innate, National, and Spiritual”... lead to an Education Plan: Inherent Knowledge, International Journal of Social Sciences, No. 173, UNESCO, Cairo, pp. 131-137. (In Arabic).

- $\quad$ Shenouda, Emile Fahmy (2012). Some global models for measuring the reality of intellectual capital and knowledge management (ff 1-16). Annual Scientific Conference (Seventh Arab International Fourth) entitled: Knowledge Management and Intellectual Capital Management in Higher Education Institutions in Egypt and the Arab World, Faculty of Specific Education in Mansoura and its two branches in Mit Ghamr and Menia ElNasr, Mansoura University, Egypt. (In Arabic).

- Solomon, the beauty of David. (2009). Knowledge Economy, Dar Al Yazouri for Publishing and Distribution, Amman, Jordan. (In Arabic).

- $\quad$ Starovic, D. and Marr, B. (2016). Understanding Corporate Value: Managing and Reporting Intellectual Capital. The Chartered Institute of Management Accountants (CIMA) and Cranfield University, London. http://www.cimaglobal.com/Documents/ImportedDocuments/intellectualca pital.pdf 
- Tapscott, D. (2014). The digital economy. Anniversary Edition: Rethinking promise and peril in the age of networked intelligence. New York: McGraw-Hill.

- Tausan, L. (2013). Education for All: A Dimension of Education in the 3rd Millennium, Social and Behavioral Sciences 82,319 - 324 .

- Taylor, S. (2017). Contested knowledge: A critical review of the concept differentiation in teaching and learning. WJETT, 1, 55-68.

- Terwel, J. (2004). Curriculum and curriculum differentiation. In Curriculum as a Shaping Force: Toward a Principled Approach in Curriculum Theory and Practice, Terwel, J. and Walker, D. (Eds.), 33-50. Hauppauge, NY: Nova Science.

- Terwel, J. (2005). Curriculum differentiation: multiple perspectives and developments in education. Journal of Curriculum Studies, 37(6), 653-670.

- Terwel, J. and Walker, D. (Eds.) (2004). Curriculum as a Shaping Force: Toward a Principled Approach in Curriculum Theory and Practice, Hauppauge, NY: Nova Science.

- Thomsen, J. (2012). Exploring the heterogeneity of class in higher education: social and cultural differentiation in Danish University programmes. British Journal of Sociology of Education, 33(4), 565-585.

- Tomlinson, C. (2008). The goals of differentiation differentiated instruction helps students not only master content, but also form their identities as learners. Educational Leadership, 66(3), 1-6.

- Valiande, S. ; Kyriakides, L. and Koutselini, M. (2011). Investigating the impact of differentiated instruction in mixed ability classrooms: Its impact on the quality and equity dimensions of education effectiveness. In International Congress for School Effectiveness and Improvement, January 2011.

- Varnava-Marouchou, M. (2004). The new millennium: implications for learning and teaching in higher education. Paper presented at the British 
Educational Research Association Annual Conference, University of Manchester, 16-18 September 2004.

- Vickerman, P. (2009). Differentiation - guidance for inclusive teaching.

Available

at:

http://webarchive.nationalarchives.gov.uk/20101021152907/http:/www.ttrb .ac.uk/ViewArticle2 .aspx ?anchorId $=17756 \&$ selectedId $=17759 \&$ menu $=178$ 34\&expanded=False $\&$ ContentId $=15712$

- Weselby, C. (2014). What is Differentiated Instruction? Examples of How to Differentiate Instruction in the Classroom. Available at: https://education.cu-portland.edu/blog/classroom-resources/examples-ofdifferentiated-instruction/

- West, J., and West, C. (2016). Integrating Differentiation in English Education Methods Courses: Learning from the Perceptions and Experiences of Teacher Candidates. The Teacher Educator, 51 (2), 115-135.

- White, D.S., Gunasekaran, A., and Ariguzo, G. (2012). The structural components of a knowledge-based economy. International Journal of Business Innovation and Research, 7(4), 504-518.

- Wu, E. (2013). The Path Leading to Differentiation: An Interview With Carol Tomlinson. Journal of Advanced Academics, 24 (2), 125-133.

- $\quad$ Zayed, Ahmad (2006). Psychology of Inter-Community Relations: Issues in Social Identity and Self-Classification, Knowledge World Series, Issue 326, National Council for Culture, Arts and Letters, Kuwait. (In Arabic).

- Zook, C. (2018). 21st Century skills. Available at: https://www.aeseducation.com/careercenter21/what-are-21st-century-skills 